\title{
Stratospheric lifetime ratio of CFC-11 and CFC-12 from satellite and model climatologies
}

\author{
L. Hoffmann ${ }^{1}$, C. M. Hoppe ${ }^{2}$, R. Müller ${ }^{2}$, G. S. Dutton ${ }^{3}$, J. C. Gille ${ }^{4,5}$, S. Griessbach ${ }^{1}$, A. Jones ${ }^{6}$, C. I. Meyer ${ }^{1}$, \\ R. Spang ${ }^{2}$, C. M. Volk ${ }^{7}$, and K. A. Walker ${ }^{6,8}$ \\ ${ }^{1}$ Jülich Supercomputing Centre, Forschungszentrum Jülich, Jülich, Germany \\ ${ }^{2}$ Institut für Energie- und Klimaforschung, Forschungszentrum Jülich, Jülich, Germany \\ ${ }^{3}$ NOAA Earth System Research Laboratory, Global Monitoring Division, Boulder, CO, USA \\ ${ }^{4}$ National Center for Atmospheric Research, Boulder, CO, USA \\ ${ }^{5}$ Center for Limb Atmospheric Sounding, University of Colorado, Boulder, CO, USA \\ ${ }^{6}$ Department of Physics, University of Toronto, Toronto, Canada \\ ${ }^{7}$ Bergische Universität Wuppertal, Fachbereich Physik, Wuppertal, Germany \\ ${ }^{8}$ Department of Chemistry, University of Waterloo, Waterloo, Ontario, Canada \\ Correspondence to: L. Hoffmann (1.hoffmann@fz-juelich.de)
}

Received: 12 May 2014 - Published in Atmos. Chem. Phys. Discuss.: 25 June 2014

Revised: 16 October 2014 - Accepted: 27 October 2014 - Published: 27 November 2014

\begin{abstract}
Chlorofluorocarbons (CFCs) play a key role in stratospheric ozone loss and are strong infrared absorbers that contribute to global warming. The stratospheric lifetimes of CFCs are a measure of their stratospheric loss rates that are needed to determine global warming and ozone depletion potentials. We applied the tracer-tracer correlation approach to zonal mean climatologies from satellite measurements and model data to assess the lifetimes of $\mathrm{CFCl}_{3}$ (CFC-11) and $\mathrm{CF}_{2} \mathrm{Cl}_{2}$ (CFC-12). We present estimates of the CFC-11 / CFC-12 lifetime ratio and the absolute lifetime of CFC-12, based on a reference lifetime of 52 years for CFC11. We analyzed climatologies from three satellite missions, the Atmospheric Chemistry Experiment-Fourier Transform Spectrometer (ACE-FTS), the HIgh Resolution Dynamics Limb Sounder (HIRDLS), and the Michelson Interferometer for Passive Atmospheric Sounding (MIPAS). We found a CFC-11 / CFC-12 lifetime ratio of $0.47 \pm 0.08$ and a CFC12 lifetime of 112(96-133) years for ACE-FTS, a ratio of $0.46 \pm 0.07$ and a lifetime of 113(97-134) years for HIRDLS, and a ratio of $0.46 \pm 0.08$ and a lifetime of $114(98-136)$ years for MIPAS. The error-weighted, combined CFC-11 / CFC12 lifetime ratio is $0.46 \pm 0.04$ and the CFC-12 lifetime estimate is $113(103-124)$ years. These results agree with the recent Stratosphere-troposphere Processes And their Role in Climate (SPARC) reassessment, which recommends life-
\end{abstract}

times of 52(43-67) years and 102(88-122) years, respectively. Having smaller uncertainties than the results from other recent studies, our estimates can help to better constrain CFC-11 and CFC-12 lifetime recommendations in future scientific studies and assessments. Furthermore, the satellite observations were used to validate first simulation results from a new coupled model system, which integrates a Lagrangian chemistry transport model into a climate model. For the coupled model we found a CFC-11 / CFC-12 lifetime ratio of $0.48 \pm 0.07$ and a CFC-12 lifetime of 110(95-129) years, based on a 10-year perpetual run. Closely reproducing the satellite observations, the new model system will likely become a useful tool to assess the impact of advective transport, mixing, and photochemistry as well as climatological variability on the stratospheric lifetimes of long-lived tracers.

\section{Introduction}

Monitoring the global distributions of chlorofluorocarbons (CFCs) is important for various reasons. The chlorine released by photolytic decomposition of CFCs plays a key role in ozone depletion both in the upper stratosphere and in the polar regions (Molina and Rowland, 1974; Solomon, 1999). Furthermore, CFCs and most of their replacements are strong 
infrared absorbers that contribute significantly to the anthropogenic greenhouse effect (Velders et al., 2007; Hodnebrog et al., 2013). Tracer-tracer relations of long-lived trace gases, such as CFCs, are frequently examined to study dynamical processes in the stratosphere, in particular the mixing of air masses near the subtropical and polar vortex transport barriers (Volk et al., 1996; Waugh, 1997; Plumb et al., 2000; Müller et al., 2001; Morgenstern et al., 2002). The data are also used to determine the age of air (Waugh et al., 2003; Schoeberl et al., 2005). Continuous, global measurements of CFCs are useful assets to validate the representation of transport, mixing, and photochemistry in atmospheric models (Eyring et al., 2005; Rind et al., 2007; Hoppe et al., 2014). Here we focus on $\mathrm{CFCl}_{3}$ (CFC-11) and $\mathrm{CF}_{2} \mathrm{Cl}_{2}$ (CFC-12), which are the CFCs with the largest atmospheric abundances.

CFCs originate from anthropogenic emissions in the troposphere, where they are well mixed and chemically stable. In the stratosphere they are removed mainly by means of photolytic decomposition and reaction with atomic oxygen. Their trends are controlled by the balance of the tropospheric sources and the stratospheric sinks. The lifetime $\tau$ (in years) is one particular measure of the global loss rate of a longlived trace gas. It is defined as the ratio

$\tau=\frac{B}{S}$

of the atmospheric burden $B$ and the sink $S$. The burden $B$ is defined as the total mass of the gas (in Tg) integrated over the atmospheric reservoir. The sink $S$ represents the total loss of mass (in $\mathrm{Tg} \mathrm{yr}^{-1}$ ). For the CFCs we usually refer to the lifetimes as "stratospheric lifetimes", because the sinks are mostly located in the stratosphere. For CFC-11 it was recently recognized that there is a minor sink in the tropical upper troposphere (SPARC, 2013), which is, however, neglected in our analysis. The stratospheric lifetimes of CFCs are crucial in determining their global warming potentials and ozone depletion potentials; see WMO (2011) and IPCC (2013) for a more detailed discussion.

Based on various lifetime estimates derived from observations, laboratory data, and a range of modeling approaches, the World Meteorological Organization (WMO) recommended lifetimes of 45 years for CFC-11 and 100 years for CFC-12 in the 1998 Scientific Assessment of Ozone Depletion (WMO, 1999). These recommendations were retained unaltered during the following three assessments. However, later studies (Douglass et al., 2008) and the WMO assessment in 2010 (WMO, 2011) indicated problems with the lifetime estimates of some halogen-containing species. As a consequence, the lifetimes of many long-lived compounds, including CFC-11 and CFC-12, have been recently reassessed within a Stratosphere-troposphere Processes And their Role in Climate (SPARC) project (SPARC, 2013). The aims of the SPARC project were to provide new estimates of the lifetimes and associated errors of many long-lived trace gases, to assess the influence of different lifetime definitions, and to assess the effect of a changing climate on lifetimes. The project results will be used to update the lifetime recommendations of the next WMO assessment. The lifetime recommendations from the SPARC project are 52(43-67) years for CFC-11 and 102(88-122) years for CFC-12. The errors given here for the SPARC data indicate "most likely" ranges and denote $2 \sigma$ uncertainties. In this study we aimed at providing new estimates of the ratio of the stratospheric lifetimes of CFC-11 and CFC-12 based on satellite observations and model output, which can be helpful input for future reassessments.

Various methods have been developed to determine the lifetimes of long-lived species from measurements or model output. In this study we apply the tracer-tracer correlation approach (Plumb and Ko, 1992; Plumb, 1996; Volk et al., 1997) to estimate the ratio of the stratospheric lifetimes of CFC-11 and CFC-12. Following a common convention, we use the lifetime ratio to also estimate the absolute lifetime of CFC-12, based on a given reference lifetime for CFC11. We here make use of the new SPARC recommendation of 52 years for CFC- 11 . Note that all CFC-12 lifetime estimates presented in this paper will change if the reference lifetime for CFC- 11 changes. We directly apply the tracer-tracer analysis to multi-annual zonal mean climatologies of CFC11 and CFC-12 that are derived from satellite measurements or atmospheric model output. This is a simple and efficient approach, as it separates the task of lifetime estimation from the task of preparing a climatology, which typically requires the processing of large satellite or model data sets. An important difference compared to previous studies using satellite data is that we used in situ surface measurements rather than satellite data to estimate the global burdens of CFC-11 and CFC-12. This yields more accurate results because the in situ measurements are much less affected by systematic errors or data gaps, which are typical for limb and occultation satellite measurements in the troposphere. The high degree of consistency of the results for the different and, except for use of the same lists of spectral lines, independent data sets analyzed here provides confidence in the validity of our approach.

In Sect. 2 we introduce the tracer-tracer correlation method used to estimate the CFC-11 / CFC-12 lifetime ratio from zonal mean climatologies. We also describe the different satellite observations and the model data set. In Sect. 3 we present estimates of the CFC-11 / CFC-12 lifetime ratio and the CFC-12 lifetime for the different data sets. Section 4 shows a comparison with lifetime estimates from other studies and provides a discussion of the results. Appendix A illustrates the influence of systematic measurement errors on lifetime analyses, based on tests with idealized CFC profiles. Appendix B describes the electronic supplement of this paper. 


\section{Methods and data}

\subsection{Lifetime estimates from tracer-tracer correlations}

The tracer-tracer approach to estimate stratospheric lifetimes of long-lived species is based on the theoretical work of Plumb and Ko (1992), Plumb (1996), and Volk et al. (1997). In these studies it is shown that any two species whose local lifetimes are longer than quasi-horizontal transport timescales are in climatological slope equilibrium. This means that they share surfaces of constant volume mixing ratios so that a scatter plot of their volume mixing ratios shows a compact curve. If this surface is chosen to lie below all sinks, the slope of the correlation curve can be related to the ratio of the tracer lifetimes,

$\frac{\tau_{1}}{\tau_{2}}=\frac{B_{1}}{B_{2}} \frac{\mathrm{d} \sigma_{2}}{\mathrm{~d} \sigma_{1}}$,

where $\tau_{1}$ and $\tau_{2}$ denote the lifetimes, $B_{1}$ and $B_{2}$ are the global burdens, and $\mathrm{d} \chi_{2} / \mathrm{d} \chi_{1}$ is the correlation slope under steady-state conditions. For stratospheric tracers such as CFCs, Eq. (2) holds at the tropopause.

Before we discuss the estimation of the stratospheric lifetimes of CFCs in more detail, we first summarize the arguments leading to the conclusion that data from the lower stratosphere at midlatitudes are best suited for that purpose. In general, the correlations of long-lived tracers are affected by the rates and locations of their sources and sinks as well as the typical characteristics of advective and diffusive fluid dynamical transport. Compact correlations are found if the chemical sources and sinks are weak and if mixing on isentropic surfaces is much faster than diabatic advection through those surfaces (Plumb, 2007). While the sources of the CFCs are located at the Earth's surface, the decomposition takes place mostly at low and midlatitudes in the middle and upper stratosphere (Minschwaner et al., 2013; Chipperfield et al., 2014). The tropical stratosphere is dominated by large-scale upwelling and is relatively isolated from midlatitudes (Volk et al., 1996; Neu and Plumb, 1999). Thus tropical correlation curves are influenced by local tropical sinks rather than reflecting only global sinks and are therefore generally not suited to derive global stratospheric lifetimes. At high latitudes the polar vortex causes stratospheric air to subside in isolation from midlatitudes and correlation curves within the vortex develop separately from those at midlatitudes over the course of the winter (Müller et al., 1996, 2005; Plumb et al., 2000; Morgenstern et al., 2003). Finally, in the free troposphere, complex advection and mixing processes can cause the breakdown of the compact, stratospheric correlations. In particular, fast vertical transport by convection violates the assumption that diabatic advection is slow compared with isentropic mixing (Plumb, 2007)

Equation (2) strictly applies only for steady-state conditions for which sources and sinks are balanced and for which the burdens do not change over time. In reality, depending on the age of air, the surface trends affect the stratospheric volume mixing ratios in different regions at different times. As a consequence, the observed transient correlation slopes $\mathrm{d} \chi_{2} / \mathrm{d} \chi_{1}$, with transient volume mixing ratios $\chi_{i}$, typically do not match with steady-state slopes $\mathrm{d} \sigma_{2} / \mathrm{d} \sigma_{1}$, with steadystate volume mixing ratios $\sigma_{i}$. Volk et al. (1997) introduced correction factors $C_{i}$ for each tracer, which depend on the correlations between the age of air and the tracer volume mixing ratio, to correct for the transience effect. Thereby the equation for the lifetime ratio becomes

$\frac{\tau_{1}}{\tau_{2}}=\frac{B_{1}}{B_{2}} \frac{\mathrm{d} \chi_{2}}{\mathrm{~d} \chi_{1}} \frac{C_{2}}{C_{1}}$.

Equation (3) is used here to estimate the lifetime ratio of CFC-11 and CFC-12 and to estimate the lifetime of CFC12 , based on a given lifetime for CFC-11. In the following we will discuss the three factors in Eq. (3) that determine the lifetime ratio in more detail.

The first factor in Eq. (3) is the ratio of the burdens $B_{1} / B_{2}$. This factor could, in principle, be determined directly from satellite or model climatologies. However, infrared limb or occultation satellite measurements in the troposphere are often affected by systematic errors, including, e.g., uncertainties in radiometric and spectral calibration or pointing knowledge. Forward model parameters errors such as uncertainties of spectroscopic data are another important error source in the CFC retrievals. Furthermore, the total number of observations in the troposphere is often limited due to the interference of clouds. As a consequence, zonal mean climatologies from satellite instruments typically have limited data quality in the troposphere. At their lowermost altitudes the climatologies often do not converge to surface values, which are very accurately known from in situ measurements. Therefore we estimated the ratio of burdens based on global mean volume mixing ratios at the surface, $\sigma_{\mathrm{s}, 1}$ and $\sigma_{\mathrm{s}, 2}$,

$\frac{B_{1}}{B_{2}}=\alpha \frac{\sigma_{\mathrm{s}, 1}}{\sigma_{\mathrm{s}, 2}}$.

This approach is motivated by the fact that more than $90 \%$ of the mass of CFC-11 and CFC-12 is located in the troposphere. In the troposphere CFCs are well mixed and their concentrations are well known from in situ measurements. Differences between the ratio of the burdens and the ratio of the surface volume mixing ratios arise from the different stratospheric distributions of the CFCs. To take into account the stratospheric distributions, we apply a scaling factor $\alpha=0.97 \pm 0.01$ to convert the ratio of surface values to the ratio of total atmospheric burdens. This value of $\alpha$ specifically applies to the ratio of CFC-11 and CFC-12. It was estimated from data reported by Volk et al. (1997, Table 3) and Brown et al. (2013, Table A4). We also confirmed it independently with the model data set described in Sect. 2.3 by comparing pressure- and cosine latitude-weighted averages 


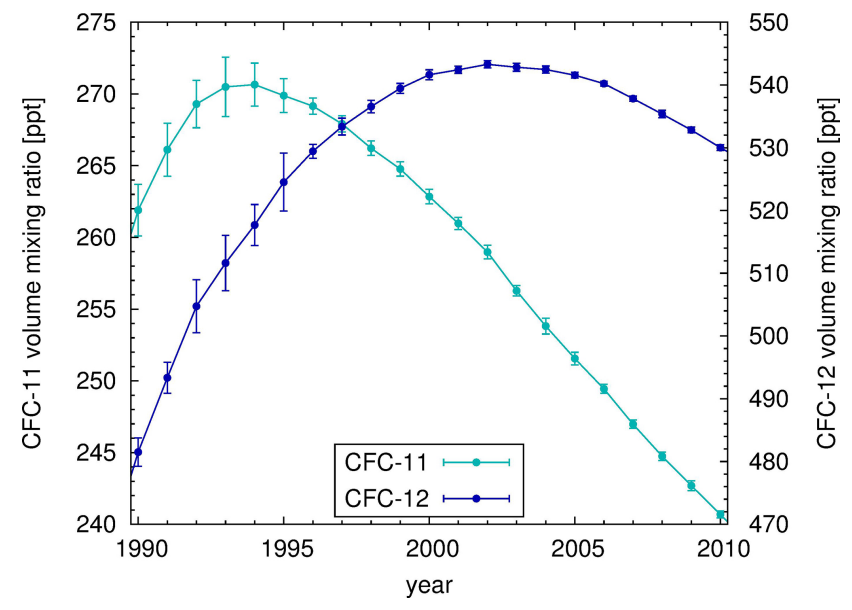

Figure 1. Annual global means of CFC-11 and CFC-12 volume mixing ratios at the surface calculated from monthly data of the NOAA/ESRL halocarbons program. Error bars indicate the mean standard deviations of the monthly data.

of the zonal mean cross sections with the surface data of the model. Although the surface volume mixing ratios and burdens show significant trends, $\alpha$ was found to be rather stable in time. The small uncertainty of $\alpha$ reported here covers the differences between the various references and data sources. Model results in the troposphere are likely not affected by systematic errors as much as satellite measurements. However, we decided to apply the same approach of transferred surface data also to the model output for consistency.

Annual global mean surface data of CFC-11 and CFC12 were obtained from the National Oceanic and Atmospheric Administration/Earth System Research Laboratory (NOAA/ESRL) halocarbons program (Elkins et al., 1993; Rigby et al., 2013). ${ }^{1}$ Annual means are derived from weighted and smoothed averages of monthly mean data, which again are combined, interpolated, and smoothed for each sampling location of the NOAA/ESRL measurement network. Hemispheric and global means are estimated by means of cosine weighting by latitude. The accuracy of the data is better than $2 \%$ (Rigby et al., 2013). A time series of the data is shown in Fig. 1. The ratio of the CFC-11 and CFC- 12 surface volume mixing ratios slightly decreased from $0.48 \pm 0.02$ in 2002 to $0.45 \pm 0.02$ in 2009 , which is the time period of interest for this study.

The second factor in Eq. (3) is the transient tracer-tracer slope $\mathrm{d} \chi_{2} / \mathrm{d} \chi_{1}$. To estimate this factor we followed the approach of Volk et al. (1997), which we applied directly to the multi-annual satellite and model zonal mean climatologies of CFC-11 and CFC-12. These climatologies usually consist of sets of volume mixing ratio profiles $\chi_{1, i}$ for CFC-11 and $\chi_{2, i}$ for CFC-12 at common altitudes $z_{i}$, pressure lev-

\footnotetext{
${ }^{1}$ The NOAA/ESRL data are accessible at http://www.esrl.noaa. gov/gmd/hats/.
}

els $p_{i}$, or model levels $\zeta_{i}$ (see Sect. 2.3) for different latitude bands. As the actual vertical coordinates are not important for the tracer-tracer analysis, we simply present all data sets on approximated altitudes below. For the satellite climatologies we converted pressure levels $p_{i}$ to log-pressure altitudes, $z_{i}=H \ln \left(p_{0} / p_{i}\right)$, with a fixed scale height $H=7 \mathrm{~km}$ and surface pressure $p_{0}=1013.25 \mathrm{hPa}$. For the model we used geopotential heights. We will show vertical profiles and tracer-tracer correlations for all latitudes for reference below, but it should be noted that the lifetime analyses are based only on midlatitude data (typically from 30 to $60^{\circ} \mathrm{N} / \mathrm{S}$ ).

To estimate the tracer-tracer slope, we first sorted all correlation data points $\left(\chi_{1, i}, \chi_{2, i}\right)$ into different analysis windows, covering specific ranges of CFC-11 volume mixing ratios. Our analysis windows had a width of $100 \mathrm{ppt}$ and a nominal center shifting from 50 to $250 \mathrm{ppt}$ in steps of $5 \mathrm{ppt}$. For each window we determined the tracer-tracer slope by means of a linear fit to the data points. As the data points are unevenly distributed within the windows, we also calculated the mean CFC-11 volume mixing ratio, to which the corresponding slope from the linear fit was assigned. By shifting the analysis window from lower to higher CFC-11 volume mixing ratios, the change in the slopes from the lower stratosphere towards the tropopause can be assessed. The tracer-tracer slope at the tropopause, which is located at the CFC-11 surface volume mixing ratio, was obtained by extrapolating a linear fit through the individual slopes of the different analysis windows. This fit through the slopes was restricted to mean CFC-11 volume mixing ratios larger than 100 ppt. Smaller CFC-11 volume mixing ratios are related to data points in the middle and upper stratosphere that cannot be used to estimate lifetimes. Our error analysis takes the statistical errors of the linear fits into account. However, the leading error of the correlation slopes is due to systematic errors of the CFC data that we assumed to be $10 \%$ for each species (see Sect. 2.2 for a discussion of measurement errors).

Our method to estimate the tracer-tracer slope differs in some aspects from the approach developed by Volk et al. (1997): (i) our analysis is directly based on zonal mean climatologies, while Volk et al. (1997) binned data from individual soundings in the specific analysis windows. The latter allows for more careful filtering of data points that are below the tropopause or outside the midlatitudes. Our method assumes that the degrading effects of these outliers can be neglected because a large number of soundings is statistically combined. The method of Volk et al. (1997) was originally developed to analyze a limited number of in situ measurements from aircraft campaigns, while our study focuses on multiyear satellite records that comprise on the order of $10^{4}$ to $10^{6}$ vertical soundings each. (ii) Volk et al. (1997) used slightly smaller analysis windows, i.e., $70 \mathrm{ppt}$ rather than 100 ppt. We performed a sensitivity test with window widths between 50 and $150 \mathrm{ppt}$ and found the most stable and consistent results for $100 \mathrm{ppt}$. Differences to $70 \mathrm{ppt}$ were minor. 


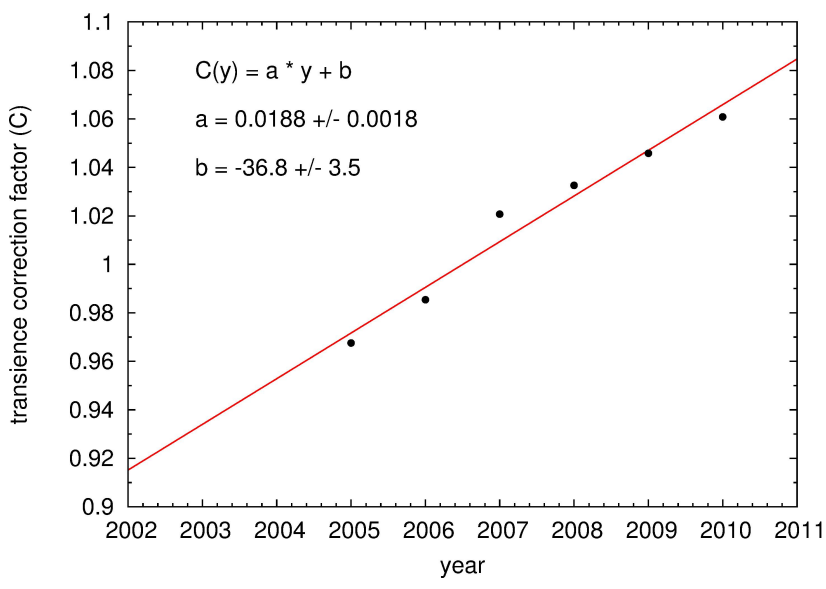

Figure 2. Combined transience correction factors $C=C_{2} / C_{1}$ for CFC-12 vs. CFC-11, which we calculated from data of Brown et al. (2013). The red line shows a linear fit to the data; see plot labels for fit parameters and statistical errors.

(iii) Volk et al. (1997) used a quadratic fit rather than a linear fit to extrapolate the slope at the tropopause. However, we found that a linear fit helps to avoid problems with increasing systematic errors of the slopes towards the tropopause (see Appendix A). The linear fit is more tightly constrained by measurements at upper altitudes. Visual inspection of the slopes for the different analysis windows helps to judge that the linear fit provides an acceptable representation.

The third factor in Eq. (3) is the ratio of correction factors $C=C_{2} / C_{1}$ for tracer transience. We determined $C$ based on data of Brown et al. (2013). Data for different years from that study are presented in Fig. 2. The results of a linear fit applied to the data are also presented. We use the fit to determine $C$ for any given reference year. In the time period from 2002 to 2009 the combined transience corrections for CFC-11 and CFC-12 range from 0.92 to 1.05 . When estimating the error of the lifetime ratio we assumed that the correction factor $C$ has an uncertainty of $5 \%$. This uncertainty is much larger than the statistical uncertainty of the linear fit, but takes into account the systematic errors of the input data. Brown et al. (2013) found that the seasonal variability of the correction factors is less than $3 \%$ each year.

\subsection{Satellite observations of CFC-11 and CFC-12}

In this study we make use of CFC-11 and CFC-12 data from three infrared limb and occultation satellite instruments: the Atmospheric Chemistry Experiment-Fourier Transform Spectrometer (ACE-FTS) (Bernath et al., 2005; Bernath, 2006), the HIgh Resolution Dynamics Limb Sounder (HIRDLS) (Gille et al., 2003, 2008, 2013), and the Michelson Interferometer for Passive Atmospheric Sounding (MIPAS) (Fischer et al., 2008). There are other data sets available for CFC-11 and CFC-12 from different satellites or from the same instruments, but analyzed with different retrieval schemes (Bingham et al., 1997; Riese et al., 1999; Yokota et al., 2002; Khosrawi et al., 2004; Kuell et al., 2005; Dinelli et al., 2010; Kellmann et al., 2012). However, these data sets have not been analyzed here. We focus on data sets covering reasonably long time periods, i. e., at least a year or longer, to capture a significant part of atmospheric variability. We also focus on data sets measured after CFC-11 and CFC12 reached their peak burdens in the years 1994 and 2002, respectively. After the peak burdens have been reached, the trends of CFC-11 and CFC-12 are slower such that the correction for transience is smaller and thus introduces less uncertainty in this type of analysis. The ACE-FTS and MIPAS data were already used in other studies to estimate the stratospheric lifetimes of CFC-11 and CFC-12 (Brown et al., 2013; Minschwaner et al., 2013). The HIRDLS data are used here for the first time for that purpose.

ACE-FTS is the main instrument on the Canadian satellite SCISAT-1. The satellite was launched into a high-inclination, circular low-Earth orbit $\left(74^{\circ}\right.$ inclination, $650 \mathrm{~km}$ altitude, 97.7 min period) in August 2003. ACE-FTS measures infrared spectra from 2.2 to $13.3 \mu \mathrm{m}$ in solar occultation mode. We make use of a quality-controlled, validated climatology of ACE-FTS data provided by the ACE Science Operations Centre at the University of Waterloo, Canada (Jones et al., 2012). ${ }^{2}$ The climatology covers the 14 baseline species for ACE-FTS, including CFC-11 and CFC-12. It is based on retrieval products obtained with processing software version 2.2 , including updates for $\mathrm{O}_{3}$ and $\mathrm{N}_{2} \mathrm{O}_{5}$. The retrievals cover an altitude range of 5 to $22 \mathrm{~km}$ for CFC- 11 and 6 to $28 \mathrm{~km}$ for CFC-12. The vertical resolution is typically 3 to $4 \mathrm{~km}$. The validation of the CFC data sets is described by Mahieu et al. (2008). It was found that ACE-FTS CFC-11 and CFC12 data are systematically lower than balloon-borne measurements. For CFC-11 the difference is $10 \%$ above $12 \mathrm{~km}$ and $20 \%$ below $12 \mathrm{~km}$. For CFC-12 the maximum bias is $10 \%$ between 12 and $28 \mathrm{~km}$. The precision of individual profiles is not relevant here because of the large number of profiles we analyzed. The ACE-FTS climatology of Jones et al. (2012) covers the time period from January 2004 to February 2009. During that time about 19000 occultation measurements were performed. The original climatological data are provided on a 3-monthly basis at $5^{\circ}$ latitude spacing and on 28 pressure levels. We averaged the 3-monthly data, giving them equal weight, to obtain a multiyear annual mean climatology. The ACE-FTS data of CFC-11 and CFC-12 are presented in Fig. 3, along with the other data sets used in this study.

HIRDLS is an infrared limb-sounding radiometer aboard the National Aeronautics and Space Administration's Aura satellite. Aura was launched into a near-polar, Sunsynchronous orbit $\left(98.2^{\circ}\right.$ inclination, $705 \mathrm{~km}$ altitude, $98.5 \mathrm{~min}$ period) in July 2004. Being in operation until

\footnotetext{
${ }^{2}$ The ACE-FTS climatology is accessible at http://www.ace. uwaterloo.ca/climatology.html.
} 

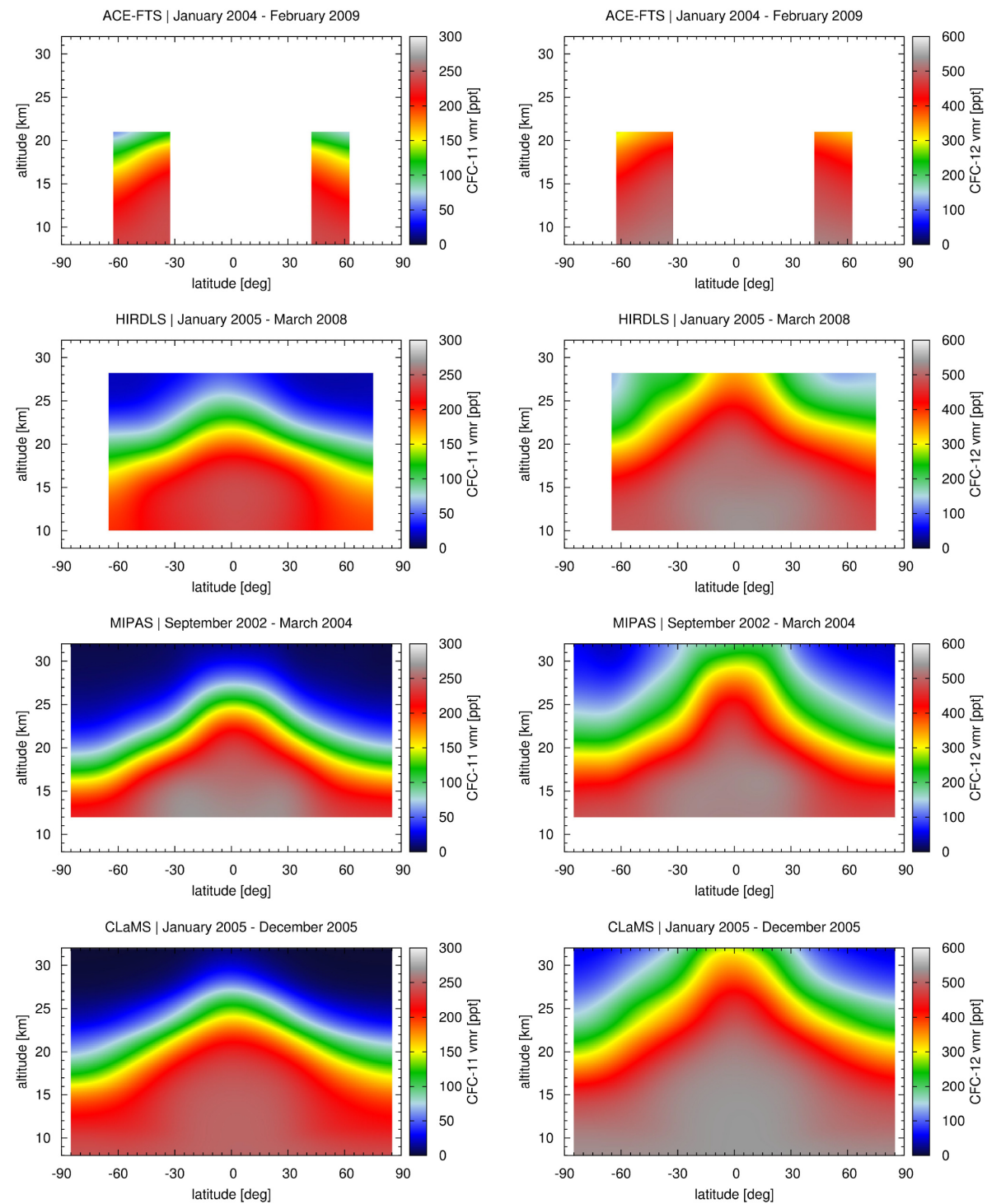

Figure 3. Zonal mean climatologies of CFC-11 (left) and CFC-12 (right) volume mixing ratios from the satellite experiments ACE-FTS, HIRDLS, and MIPAS, as well as the EMAC/CLaMS model. See plot titles for time periods covered by the different climatologies. Note that altitudes are log-pressure altitudes for the satellite climatologies and geopotential heights for the EMAC/CLaMS model.

March 2008, HIRDLS measured thermal emissions from the atmospheric limb at various spectral intervals in the range from 6 to $17 \mu \mathrm{m}$, chosen to correspond to specific trace gases such as CFC-11 and CFC-12. We analyzed retrieval products obtained with the processing software version 7 (Gille et al., 2013). ${ }^{3}$ The retrievals cover an altitude range of 8 to $26 \mathrm{~km}$ for CFC-11 and 8 to $32 \mathrm{~km}$ for CFC-12. The vertical resolution is about $1 \mathrm{~km}$. A comparison of HIRDLS and ACEFTS for August and September 2006 showed good agreement for both CFC-11 and CFC-12 (Gille et al., 2013). The bias between both instruments is mostly below $10 \%$. To de-

\footnotetext{
${ }^{3}$ The HIRDLS data are accessible at http://disc.sci.gsfc.nasa. gov/Aura/data-holdings/HIRDLS.
}

rive zonal mean climatologies from HIRDLS, we first averaged the data on the given pressure levels in $10^{\circ}$ latitude bins on a monthly basis. We filtered individual measurements that are affected by significant contributions of a priori data or for which the limb view is blocked by clouds. We also removed outliers that we identified based on volume mixing ratios exceeding the global mean surface values in 2006 by more than $10 \%$. The actual thresholds used for filtering are 275 ppt for CFC-11 and 595 ppt for CFC-12. The monthly means from January 2005 to March 2008 were averaged, giving them equal weight, to obtain a multiyear annual mean climatology of CFC-11 and CFC-12. The climatology is based on more than 6 million individual limb soundings. The data are presented in Fig. 3. 
MIPAS is one of ten instruments aboard the European Space Agency's Envisat satellite. Envisat was launched in a nearly polar, Sun-synchronous orbit $\left(98.6^{\circ}\right.$ inclination, $790 \mathrm{~km}$ altitude, $100.2 \mathrm{~min}$ period) in March 2002. After losing contact with the satellite, the end of Envisat's mission was announced in May 2012. MIPAS measured infrared spectra from 4.1 to $15.4 \mu \mathrm{m}$ in the limb-viewing geometry. We focus on observations made in between September 2002 and March 2004. During that time period the MIPAS nominal limb scans covered 6 to $68 \mathrm{~km}$ altitude with $3 \mathrm{~km}$ vertical sampling from the troposphere to the middle stratosphere. The retrieval, validation, and preparation of climatologies of the CFC-11 and CFC-12 MIPAS data used here are described by Hoffmann et al. (2004, 2005, 2008). Based on comparisons with other satellite data sets and in situ measurements, it is shown that the accuracy of the MIPAS data is about $10 \%$. The MIPAS climatologies of CFC-11 and CFC-12 are based on more than 400000 vertical soundings. The data are given on a $10^{\circ}$ latitude and $1 \mathrm{~km}$ log-pressure altitude grid. The zonal mean cross sections are shown in Fig. 3. For additional consistency tests we prepared a second MIPAS climatology (not shown here) based on the new European Space Agency (ESA) MIPAS level-2 processor version 6 data (Raspollini et al., 2013). We found that the new ESA data agree well with the data set of Hoffmann et al. (2004, 2005, 2008). The differences of the midlatitude climatological profiles were below $\pm 5 \%$ at 12 to $20 \mathrm{~km}$ altitude. This indicates that the two different forward models and retrieval schemes have only a minor impact on the results.

All three satellite instruments, ACE-FTS, HIRDLS, and MIPAS, show reasonable zonal mean cross sections. We found the expected spatial distributions due to upwelling of CFC-rich air in the tropics, decomposition of CFCs at low and midlatitudes in the middle and upper stratosphere, and downwelling of CFC-poor air in the polar regions. Having more $\mathrm{C}-\mathrm{F}$ bonds, CFC-12 is photochemically more stable and propagates higher up in the tropical stratosphere. Although the satellite data sets are obtained during different time periods, there is mostly good consistency of the zonal mean climatologies. The only significant difference found, based on visual inspection of the cross sections, is a high bias of HIRDLS CFC-12 measurements at southern midlatitudes around 20 to $30 \mathrm{~km}$ altitude. This anomaly is present in many, but not all, of the individual profiles and has already been identified by the HIRDLS team (B. Nardi, personal communication, 2013). However, at the moment no further explanation can be provided. We decided to restrict the analysis of the HIRDLS data to the Northern Hemisphere.

\subsection{Coupled chemistry climate model}

In this study we use the satellite observations to validate first simulation results obtained from a new coupled model system (Hoppe et al., 2014). The model integrates a Lagrangian chemistry transport model into a climate model.
It was mainly developed to assess the differences between Eulerian and Lagrangian transport modeling with respect to climate predictions. However, we expect that the new model will also help to improve long-term simulations of long-lived trace gases such as CFCs in the stratosphere, due to the very low numerical diffusion of the Lagrangian transport scheme. Here we demonstrate, based on a comparison of the lifetime diagnostics, that the new model system provides realistic global distributions of CFC-11 and CFC-12 with respect to transport, mixing, and photochemistry.

One component of the coupled model is the Chemical Lagrangian Model of the Stratosphere (CLaMS) (McKenna et al., 2002a, b; Grooß et al., 2002; Konopka et al., 2004). CLaMS comprises three main modules for chemistry, advection, and mixing, as well as several submodules for the simulation of various other physical and chemical processes in the atmosphere. Due to its transport scheme, which allows for a precise control of mixing intensity, CLaMS is especially well suited for simulating transport barriers in the atmosphere, e.g., at the subtropical and polar jets. The trajectory module of CLaMS calculates Lagrangian non-diffusive transport of air parcels based on numerical integration with a fourth-order Runge-Kutta scheme. Trajectory calculations are based on the hybrid vertical coordinate $\zeta$ (Mahowald et al., 2002; Konopka et al., 2007). The original CLaMS version contains a detailed stratospheric chemistry scheme that involves around 150 chemical species (McKenna et al., 2002a; Grooß et al., 2002). Here, we employed a simplified chemistry scheme that is efficient for long-term simulations (Pommrich et al., 2014). The simplified scheme uses dailymean photolysis rates and describes the first-order loss of long-lived tracers, such as CFC-11 and CFC-12. The photolysis rates were calculated as diurnal averages using the CLaMS photolysis code (Becker et al., 2000). The simplified chemistry scheme does not simulate chemical loss due to the reaction with excited-state atomic oxygen, $\mathrm{O}\left({ }^{1} \mathrm{D}\right)$. However, the contribution to global CFC loss due to the reaction with $\mathrm{O}\left({ }^{1} \mathrm{D}\right)$ is below $10 \%$ (Minschwaner et al., 2013).

The second component of the coupled model system is the ECHAM/MESSy Atmospheric Chemistry (EMAC) model. EMAC is a chemistry climate model that includes the climate model ECHAM5 (Roeckner et al., 2006) and the interface structure Modular Earth Submodel System (MESSy) (Jöckel et al., 2010). MESSy provides a coupling interface structure to develop Earth system models with the flexibility to vary between many processes that are included as submodels. MESSy includes a special submodel for dealing with atmospheric tracers (submodel TRACER; Jöckel et al., 2008). In the standard EMAC setup, tracers are transported using the flux-form semi-Lagrangian transport scheme of Lin and Rood (1996). The CLaMS modules for trajectory transport, mixing, simplified chemistry, and boundary conditions have been integrated into the MESSy interface structure as submodels. In the coupled EMAC/CLaMS model, 
ECHAM5 provides meteorological input for the CLaMS chemistry transport model.

For this study we performed a 10-year perpetual run with 2005 boundary conditions with the coupled EMAC/CLaMS model. The free-running simulation was not nudged to observations. Sea surface temperatures and sea ice concentrations were taken from the Atmospheric Model Intercomparison Project (AMIP II) climatology (Hurrell et al., 2008). The EMAC spectral resolution was T42, which corresponds to a quadratic Gaussian grid of approximately $2.8^{\circ} \times 2.8^{\circ}$ in latitude and longitude, with 90 vertical levels. For the CLaMS transport core, about 1 million air parcels were distributed from the surface up to $2500 \mathrm{~K}$ potential temperature (about $60 \mathrm{~km}$ altitude). Initial values as well as boundary conditions for chemical species were taken from a climatological run with the stand-alone CLaMS model (Konopka et al., 2007). As CFC-12 is not included in the CLaMS climatological run, its initial values for the EMAC/CLaMS simulation were obtained using three correlation functions of CFC-12 with $\mathrm{N}_{2} \mathrm{O}$ for the tropics $\left(15^{\circ} \mathrm{N}\right.$ to $\left.15^{\circ} \mathrm{S}\right)$ and the northern or southern extratropics. To prepare a zonal mean climatology, data from the years 6 to 10 of the 10-year perpetual run with EMAC/CLaMS were averaged. Years 1 to 5 were not taken into account to minimize the influence of initialization. The EMAC/CLaMS data were binned and averaged on a $10^{\circ}$ latitude grid for a set of $33 \zeta$ levels. The vertical spacing of these levels varies between 0.5 and $1.3 \mathrm{~km}$ in the upper troposphere and lower stratosphere. The EMAC/CLaMS zonal mean climatologies of CFC-11 and CFC-12 are presented in Fig. 3. Good agreement is found in comparison with the satellite measurements. Further validation of the EMAC/CLaMS simulation results is provided by Hoppe et al. (2014).

\section{Results}

In this section we present our estimates of the stratospheric lifetime ratio of CFC-11 and CFC-12 and the absolute lifetime of CFC-12 for the three satellite missions and the model. All climatologies cover several years of data, i.e., about 5 years for ACE-FTS, 3 years for HIRDLS, 1.5 years for MIPAS, and 5 years for EMAC/CLaMS. The different time periods covered by the data sets make it slightly more difficult to compare the results, but averaging over long time periods helps to reduce the influence of atmospheric variability and to constrain the results. We assigned a reference year to each data set that is used to determine the ratios of the burdens and the transience correction factors. As shown in Sect. 2, these parameters vary only slowly over time. By selecting the reference year in the middle of the time period of each data set we made sure that the errors due to a constant approximation are minor. The uncertainties of all results are given as standard deviations ( $1 \sigma$ values) and calculated based on conventional error propagation principles. Note that the CFC- 12 lifetimes have asymmetric error bars because error propaga- tion was calculated for their inverse. Following other studies, we here did not take the uncertainty of the CFC-11 reference lifetime into account when we estimated the error of the CFC-12 lifetime. The input data for the lifetime calculations according to Eq. (3) and the CFC-11 / CFC-12 lifetime ratios for the four data sets used here are summarized in Table 1.

The data used for the ACE-FTS lifetime analysis are presented in Fig. 4. The analysis is based on $5^{\circ}$ latitude bands at 60 to $35^{\circ} \mathrm{S}$ and 40 to $60^{\circ} \mathrm{N}$. For the lifetime calculations we selected the year 2006 as the reference year. The surface volume mixing ratios for the reference year are $(249 \pm 8)$ ppt for CFC-11 and (540 \pm 16$)$ ppt for CFC-12. We calculated a ratio of burdens of $0.448 \pm 0.020$ for CFC-11 vs. CFC- 12 . The linear fits yielded a correlation slope of $1.05 \pm 0.15$ for CFC-12 vs. CFC-11 at the tropopause. The ratio $C$ of transience correction factors was estimated as $0.99 \pm 0.05$. These data lead to a ratio of the steady-state lifetimes of CFC-11 and CFC-12 of $0.47 \pm 0.08$ and, assuming a lifetime of 52 years for CFC11 , an estimated lifetime of 112(96-133) years for CFC12. A separate analysis for the Northern Hemisphere only provided a lifetime of 113(97-135) years. For the Southern Hemisphere we found 110(95-131) years.

Figure 5 shows the data set used for the HIRDLS lifetime analysis. The analysis is based on $10^{\circ}$ latitude bands at 30 to $60^{\circ} \mathrm{N}$. Data from the Southern Hemisphere were not used due to data quality issues (Sect. 2.2). For the lifetime calculations we selected the year 2006 as the reference year, resulting in the same surface volume mixing ratios and ratio of burdens as for ACE-FTS. The linear fits yielded a correlation slope of $1.04 \pm 0.15$ for CFC-12 vs. CFC-11 at the tropopause. With application of the same combined transience correction factor $C$ as for ACE-FTS, this leads to a ratio of the steady-state lifetimes of CFC-11 and CFC-12 of $0.46 \pm 0.07$ and a lifetime of 112(97-134) years for CFC-12.

The data used for the MIPAS lifetime analysis are presented in Fig. 6. The analysis is based on $10^{\circ}$ latitude bands at 60 to $30^{\circ} \mathrm{S}$ and 30 to $60^{\circ} \mathrm{N}$. For the lifetime calculations we selected the year 2003 as the reference year. The surface volume mixing ratios for the reference year are $(256 \pm 8) \mathrm{ppt}$ for CFC-11 and (543 \pm 16$)$ ppt for CFC-12. We calculated a ratio of burdens of $0.458 \pm 0.020$ for CFC- 11 vs. CFC12. Compared to ACE-FTS and HIRDLS, the ratio of burdens differs only by $2 \%$. The linear fits yielded a correlation slope of $1.07 \pm 0.16$ for CFC-12 vs. CFC-11. The ratio $C$ of transience correction factors was estimated as $0.934 \pm 0.047$, i.e., a larger correction than the one used for ACE-FTS and HIRDLS. These data lead to a ratio of the steady-state lifetimes of CFC-11 and CFC-12 of $0.46 \pm 0.08$ and a lifetime of 114(98-136) years for CFC-12. A separate analysis provided a lifetime of 111(95-134) years for the Northern Hemisphere and 120(103-144) years for the Southern Hemisphere. For the ESA data the analysis gave a lifetime of 113(95-137) years globally, 114(95-140) years for the Northern Hemisphere, and 113(97-135) years for the Southern Hemisphere. While hemispheric data differ to some extent, the global 
Table 1. Summary of input data for the calculation of CFC-11 / CFC-12 lifetime ratios.

\begin{tabular}{lcccc}
\hline Data set & $B_{1} / B_{2}$ & $\chi_{2} / \chi_{1}$ & $C_{2} / C_{1}$ & $\tau_{1} / \tau_{2}$ \\
\hline ACE-FTS (2004-2009) & $0.448 \pm 0.020$ & $1.05 \pm 0.15$ & $0.991 \pm 0.050$ & $0.466 \pm 0.075$ \\
HIRDLS (2005-2008) & $0.448 \pm 0.020$ & $1.04 \pm 0.15$ & $0.991 \pm 0.050$ & $0.462 \pm 0.073$ \\
MIPAS (2002-2004) & $0.458 \pm 0.020$ & $1.07 \pm 0.16$ & $0.934 \pm 0.047$ & $0.458 \pm 0.076$ \\
EMAC/CLaMS (2005) & $0.451 \pm 0.020$ & $1.05 \pm 0.15$ & $1.000 \pm 0.000$ & $0.475 \pm 0.071$ \\
\hline
\end{tabular}
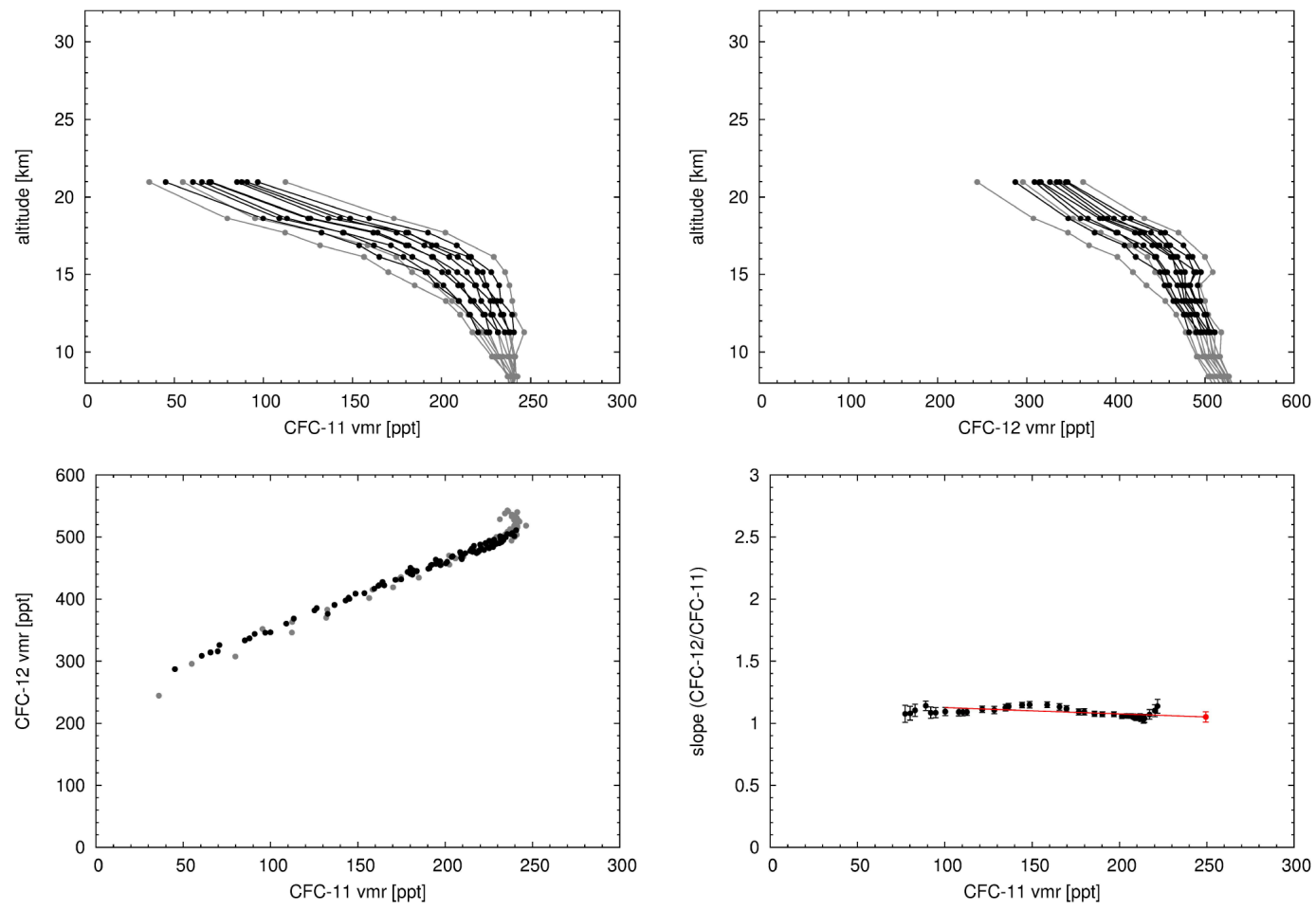

Figure 4. Volume mixing ratio (vmr) profiles of CFC-11 (top, left) and CFC-12 (top, right), tracer-tracer correlations (bottom, left), and tracer-tracer slopes (bottom, right) used to estimate lifetimes from ACE-FTS data. Black color indicates midlatitude data. Grey color indicates data from other latitudes. The red line shows a linear fit used to extrapolate the tracer-tracer slope at the tropopause (red dot).

results for the ESA data agree well with the results for the data of Hoffmann et al. (2004, 2005, 2008).

Finally, the data set used for the EMAC/CLaMS lifetime analysis is presented in Fig. 7. The analysis is based on $10^{\circ}$ latitude bands at 60 to $30^{\circ} \mathrm{S}$ and 30 to $60^{\circ} \mathrm{N}$. For the lifetime calculations we selected the year 2005 as the reference year. The surface volume mixing ratios for the reference year are $(252 \pm 8) \mathrm{ppt}$ for CFC-11 and (542 \pm 16$)$ ppt for CFC-12. We calculated a ratio of burdens of $0.451 \pm 0.020$ for CFC11 vs. CFC-12. The linear fits yielded a correlation slope of $1.05 \pm 0.15$. We did not apply a transience correction, because we assume that the model approached steady-state conditions during the last 5 years of the 10-year perpetual run. The EMAC/CLaMS model results lead to a ratio of the steady-state lifetimes of CFC-11 and CFC- 12 of $0.48 \pm 0.07$ and a CFC-12 lifetime of 110(95-129) years. We found a lifetime of 108(94-127) years for the Northern Hemisphere and 111(97-131) years for the Southern Hemisphere.

\section{Discussion and conclusions}

We applied the tracer-tracer approach of Plumb and Ko (1992), Plumb (1996), and Volk et al. (1997) to estimate the stratospheric lifetime ratio of CFC-11 and CFC-12 from ACE-FTS, HIRDLS, and MIPAS satellite observations as well as EMAC/CLaMS model output. We also estimated the absolute lifetime of CFC-12, based on a reference lifetime of 52 years for CFC-11. As discussed in Sect. 2, our approach is similar to, but differs in some aspects from, the method of Volk et al. (1997). An important difference compared to other studies using satellite data is that we estimated the ratio of burdens of CFC-11 and CFC-12 based on NOAA/ESRL in situ surface measurements rather than using the satellite 

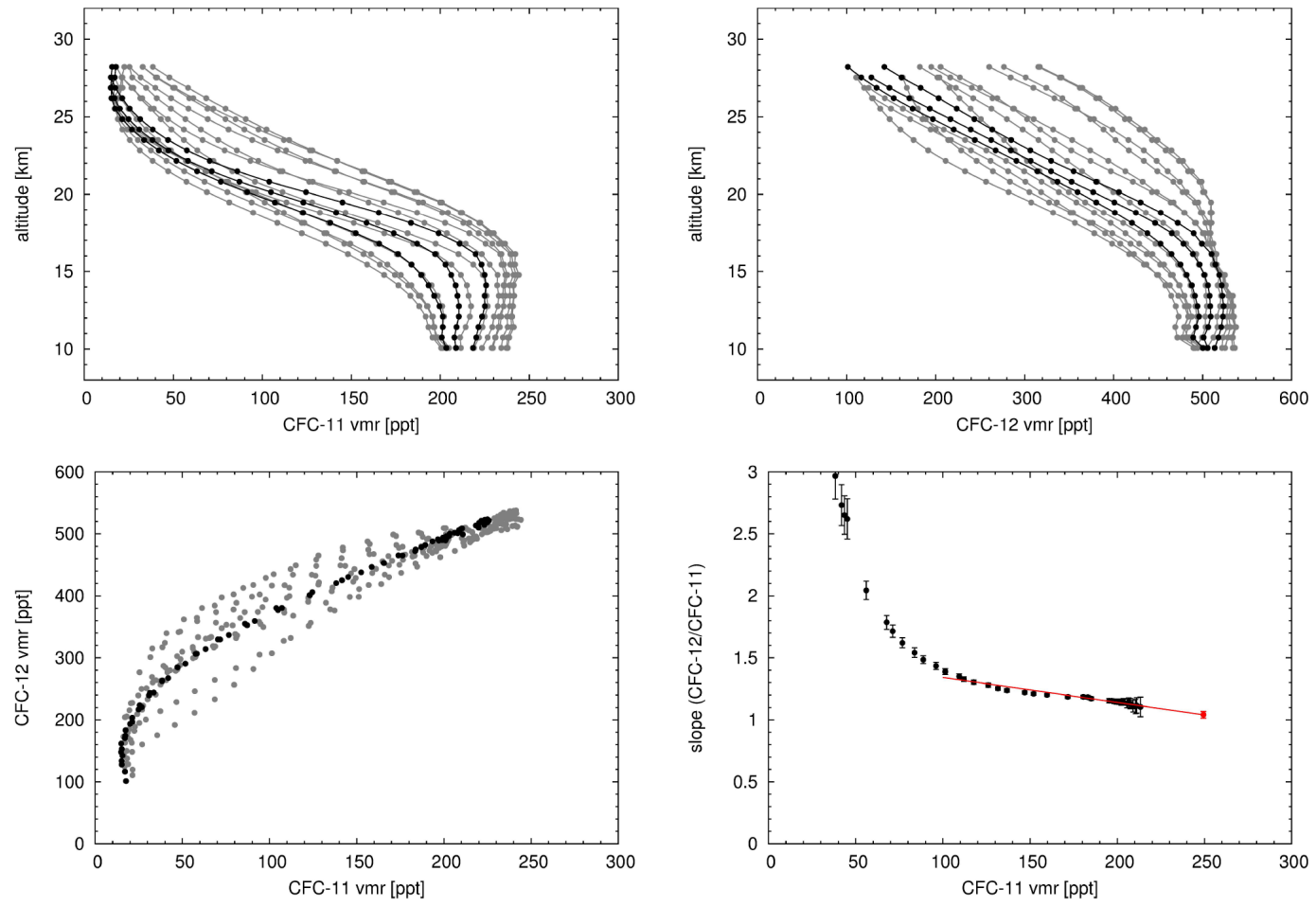

Figure 5. Same as Fig. 4, but for HIRDLS data.
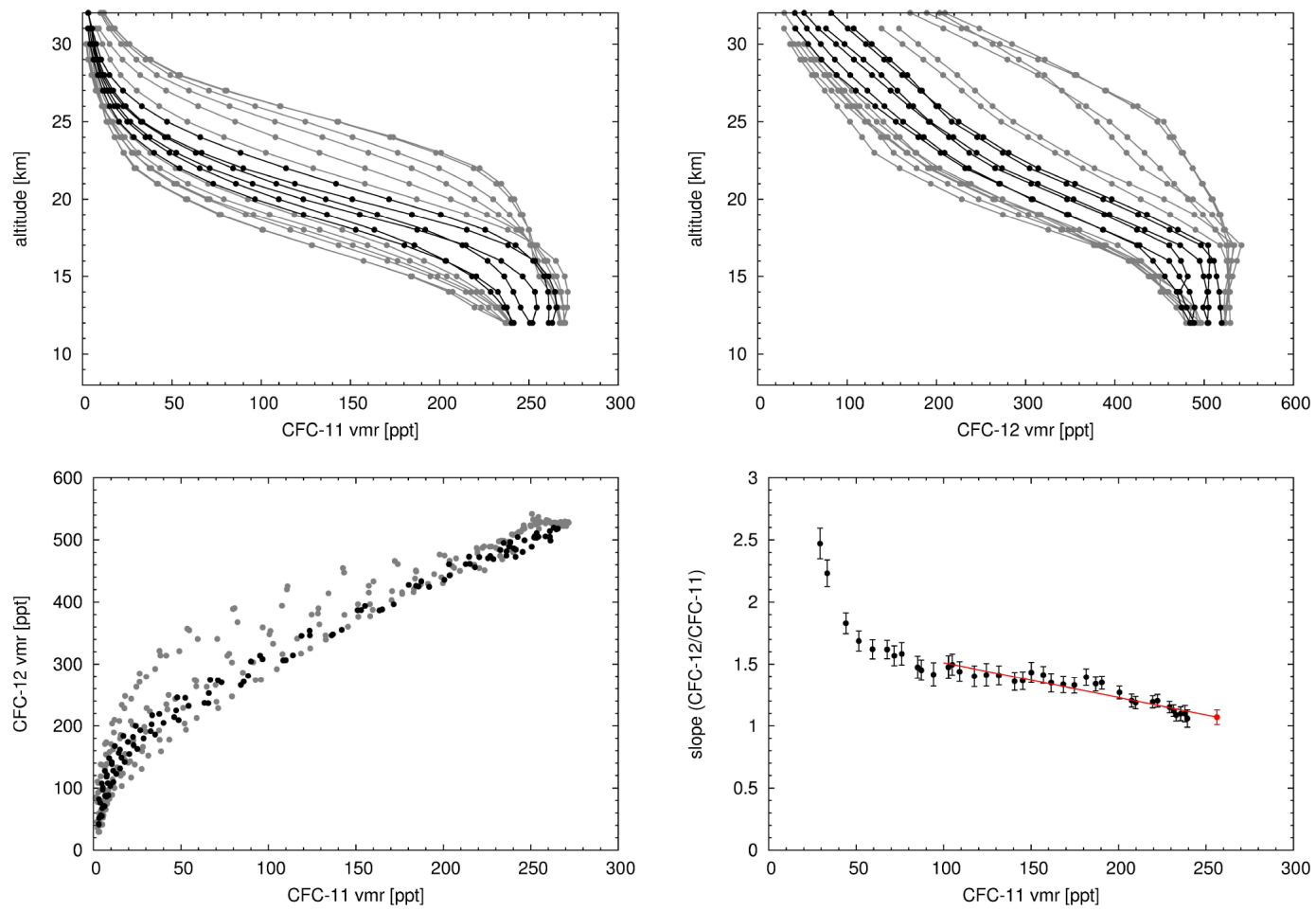

Figure 6. Same as Fig. 4, but for MIPAS data. 

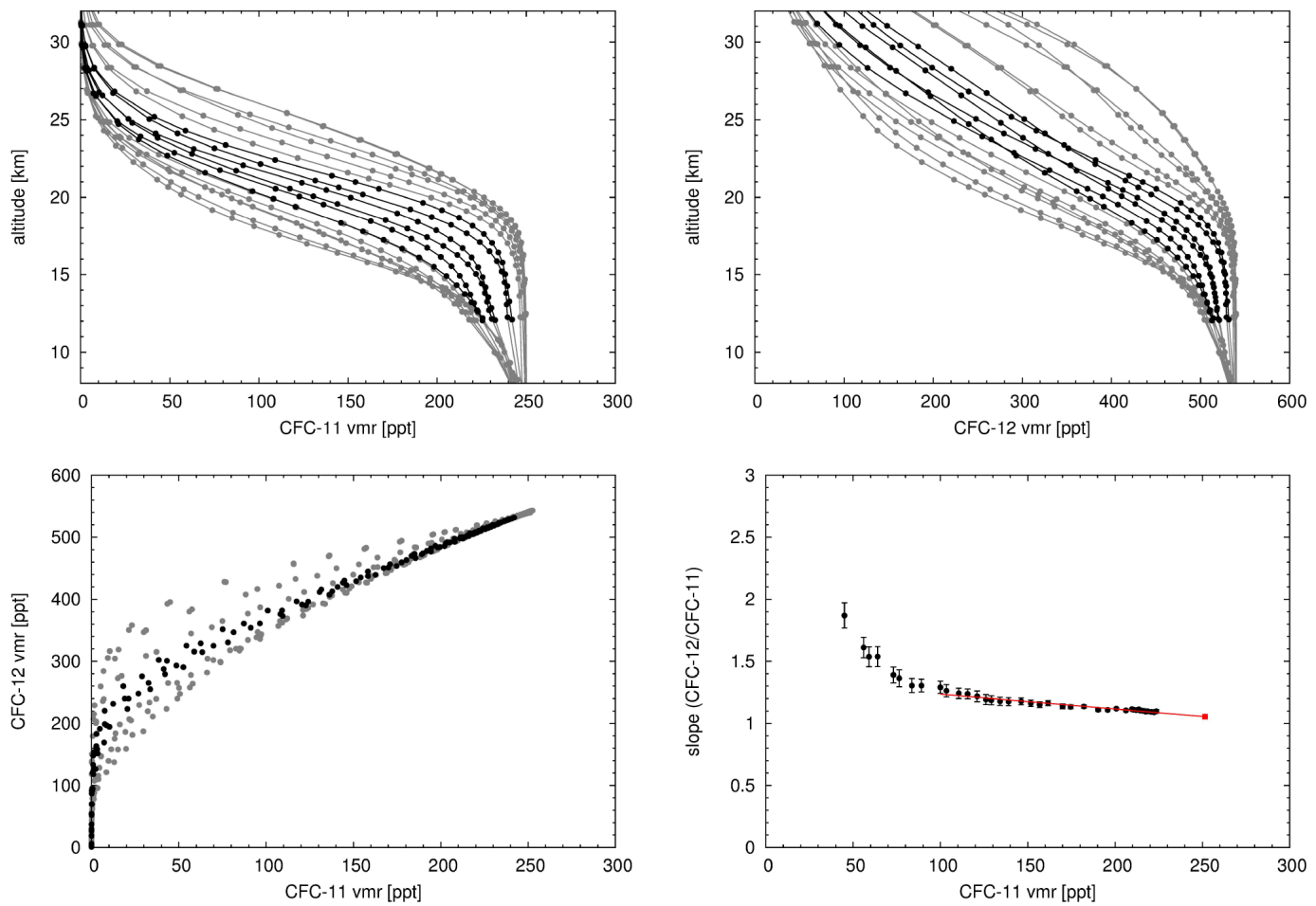

Figure 7. Same as Fig. 4, but for EMAC/CLaMS data.

data for that purpose. This avoids problems related to degraded data quality of limb and occultation satellite measurements in the troposphere due to systematic measurement errors and data gaps. Another difference between our study and the method of Volk et al. (1997) is that our analysis is based on multi-annual zonal mean climatologies that are prepared beforehand and independently from the estimation of lifetimes.

The lifetime estimates from our analysis are summarized and compared to other recent studies in Table 2. Our estimates for the three satellite data sets show a very high degree of consistency and are in good agreement with the current WMO recommendation, the new SPARC reassessment, and other work. In particular, the estimated lifetime ratios are in excellent agreement with the study of Rigby et al. (2013), which is based on data from the Advanced Global Atmospheric Gases Experiment (AGAGE) and the NOAA/ESRL ground-based networks, which are analyzed with a chemical transport model and a statistical inversion method. Compared to the study of Brown et al. (2013), who applied the method of Volk et al. (1997) on ACE-FTS data, we found a $17 \%$ larger CFC-11 / CFC-12 lifetime ratio for measurements from the same instrument. Part of the difference is due to the fact that we applied a linear fit to extrapolate the tracer-tracer slope at the tropopause, whereas Brown et al. (2013) applied a quadratic fit. If we replace the linear fit with a quadratic fit in our analysis, the differences to the results of Brown et al. (2013) are reduced to $10 \%$. However, we also found that the quadratic fit significantly increases the error of the extrapolated tracer-tracer slope and thus decided to keep the linear fit in our analysis. The ratio of burdens from our analysis is in good agreement $(\leq 0.7 \%)$ with the data reported by Brown et al. (2013). The data for the transience correction are directly obtained from Brown et al. (2013) and therefore cannot explain any significant differences. We think that the remaining differences may be due to different data sets used for the lifetime analysis. The study of Brown et al. (2013) covers ACE-FTS data version 3.0 for the years 2005 to 2010 , whereas in our study the Jones et al. (2012) climatology based on version 2.2 was used, covering the years 2004 to 2009. In addition, the median average deviation filtering for each data set was applied using different altitude, spatial and temporal bins. Our CFC-11 / CFC-12 lifetime ratio for MIPAS is $39 \%$ larger than the corresponding estimate of Minschwaner et al. (2013). Both analyses are based on the same climatology. However, very different analysis techniques were used. Minschwaner et al. (2013) applied a photochemical model with additional input parameters to determine the CFC global loss rates. These are used to estimate absolute lifetimes rather than a lifetime ratio. The results of Minschwaner et al. (2013) mostly depend on CFC data in the middle and upper stratosphere at equatorial latitudes, whereas our results depend on data from the midlatitude lower stratosphere.

In our study the results for the three satellite missions show excellent agreement among each other. The 
Table 2. Comparison of stratospheric lifetime estimates of CFC-11 and CFC-12 from different studies. The table lists the data sources of the studies and if absolute (abs) or relative (rel) lifetime estimates are provided. All relative lifetime estimates are normalized to a CFC11 lifetime of 52 years. A sub- and superscript notation is used to report errors. Note that error definitions vary between the studies (see individual references). In particular, for SPARC (2013) the errors represent $2 \sigma$ uncertainties.

\begin{tabular}{|c|c|c|c|c|c|}
\hline Reference & Data source & Method & $\begin{array}{c}\tau(\mathrm{CFC}-11) \\
\text { [years] }\end{array}$ & $\begin{array}{c}\tau(\mathrm{CFC}-12) \\
\text { [years] }\end{array}$ & Ratio \\
\hline \multirow[t]{4}{*}{ This study } & ACE-FTS & rel & 52 & $112_{96}^{133}$ & $0.47_{0.39}^{0.54}$ \\
\hline & HIRDLS & rel & 52 & $113_{97}^{134}$ & $0.46_{0.39}^{0.54}$ \\
\hline & MIPAS & rel & 52 & $114_{98}^{136}$ & $0.46_{0.38}^{0.53}$ \\
\hline & EMAC/CLaMS & rel & 52 & $110_{95}^{129}$ & $0.48_{0.40}^{0.55}$ \\
\hline SPARC (2013) & various & both & $52_{43}^{67}$ & $102_{88}^{122}$ & $0.51_{0.35}^{0.76}$ \\
\hline Brown et al. (2013) & ACE-FTS & rel & 52 & $131_{110}^{161}$ & $0.40_{0.32}^{0.47}$ \\
\hline Chipperfield et al. (2014) & model results & abs & 55 & 95 & 0.58 \\
\hline Laube et al. (2013) & aircraft data & rel & 52 & $87_{77}^{97}$ & $0.60_{0.54}^{0.67}$ \\
\hline McGillen et al. (2013) & model results & abs & 58 & - & - \\
\hline \multirow[t]{6}{*}{ Minschwaner et al. (2013) } & ACE-FTS & abs & $46_{36}^{65}$ & $105_{84}^{139}$ & $0.44_{0.26}^{0.77}$ \\
\hline & CLAES & abs & - & $108_{88}^{140}$ & - \\
\hline & CRISTA-1 & abs & $53_{41}^{75}$ & - & - \\
\hline & CRISTA-2 & abs & $61_{47}^{86}$ & - & - \\
\hline & MIPAS & abs & $36_{28}^{50}$ & $108_{83}^{151}$ & $0.33_{0.19}^{0.60}$ \\
\hline & combined & abs & $45_{36}^{58}$ & $107_{90}^{130}$ & $0.42_{0.28}^{0.64}$ \\
\hline \multirow[t]{2}{*}{ Rigby et al. (2013) } & AGAGE & abs & $54_{48}^{61}$ & $111_{95}^{132}$ & $0.49_{0.36}^{0.64}$ \\
\hline & NOAA/ESRL & abs & $52_{45}^{61}$ & $112_{95}^{136}$ & $0.46_{0.33}^{0.64}$ \\
\hline WMO (2011) & various & both & 45 & 100 & 0.45 \\
\hline Douglass et al. (2008) & model results & abs & $60_{56}^{64}$ & $106_{101}^{110}$ & $0.57_{0.51}^{0.63}$ \\
\hline \multirow[t]{2}{*}{ Volk et al. (1997) } & aircraft data & abs & $41_{29}^{53}$ & $77_{51}^{103}$ & $0.53_{0.3}^{0.76}$ \\
\hline & & rel & 52 & $99_{87}^{112}$ & $0.52_{0.45}^{0.59}$ \\
\hline
\end{tabular}

CFC-11 / CFC-12 lifetime ratios vary only by $1.7 \%$ and the CFC-12 lifetime estimates vary only by 2 years. Consequently, we combined the ACE-FTS, HIRDLS, and MIPAS results to obtain error-weighted optimal estimates. This led to a CFC-11 / CFC-12 lifetime ratio of $0.46 \pm 0.04$ and a CFC-12 lifetime of 113(103-124) years. The combined results are in very good agreement with the current WMO recommendation $(\leq 3 \%)$ and in good agreement with the new SPARC reassessment $(\leq 10 \%)$. The WMO assessment in 2010 showed a $60 \%$ difference between 2005 and 2008 "bottom-up" and "top-down" emission estimates for CFC11, while good agreement was found for CFC-12 (WMO, 2011). As "top-down" estimates critically depend on the lifetimes, whereas "bottom-up" estimates do not, it was further demonstrated (WMO, 2011) that a longer CFC-11 life- time (64 years rather than 45 years) and thus a larger CFC11 / CFC-12 lifetime ratio could resolve this discrepancy. Our study indicates that the CFC-11 / CFC-12 lifetime ratio is about $3 \%$ larger than the current WMO recommendation. This explains only some of the discrepancy identified in the last WMO assessment. However, a larger ratio was found in the new SPARC assessment. An important benefit of our study is that the errors of the combined data are up to a factor of 2 smaller than the error estimates of other recent studies. We conclude that our results can contribute to further constraining the reference values for the CFC-11 and CFC-12 lifetimes in future assessments and scientific studies.

The stratospheric lifetimes of long-lived tracers such as CFC-11 and CFC-12 are important diagnostic quantities to evaluate the representation of transport and mixing in 
atmospheric models. Douglass et al. (2008) point out that models with faster circulation produce younger age-of-air distributions and that increasing circulation speed leads to shorter CFC lifetimes. A comparison of CFC lifetimes from a model and from observations therefore allows for a judgement to be made regarding whether the model appropriately represents important features of the stratospheric circulation. We used the satellite results to validate the new EMAC/CLaMS coupled model system. As we applied exactly the same method to estimate the lifetimes for the satellite observations and the model, the results are indeed indicative of differences in the underlying data and are not affected by differences that could occur if different methods for lifetime estimation were to be used. We found that the EMAC/CLaMS results are in excellent agreement $(\leq 3 \%)$ with the satellite observations after a spin-up phase of 5 years. However, the CFC-11 / CFC-12 lifetime ratio found here is about $17 \%$ smaller than the result of the recent multimodel study of Chipperfield et al. (2014). On the one hand, it should be noted that our simulations are based on a simplified chemistry scheme that neglects CFC loss due to reaction with excited-state atomic oxygen (Sect. 2.3). However, this is only a minor loss mechanism. On the other hand, we put forward that the Lagrangian transport scheme of EMAC/CLaMS provides an improved representation of advection and mixing in the stratosphere (Hoppe et al., 2014). The Lagrangian transport scheme used by EMAC/CLaMS is fundamentally different from the other schemes used by the models discussed by Chipperfield et al. (2014). We conclude that the new EMAC/CLaMS model will likely become a useful tool to assess the impact of advective transport, mixing, and photochemistry as well as climatological variability on the stratospheric lifetimes of long-lived tracers.

Another topic of interest is the spatial and temporal variability of lifetime estimates. Rossby wave breaking and mixing in the stratosphere are typically much stronger in the winter hemisphere than in the summer hemisphere (Holton et al., 1995; Plumb, 2002). Furthermore, because of the larger continental land masses in the Northern Hemisphere, the northern stratosphere has more frequent and intense planetary wave activity than the southern stratosphere (Holton et al., 1995; Plumb, 2007). Stronger wave activity in Northern Hemisphere winter leads to a faster Brewer-Dobson circulation in the stratosphere. Model calculations show that faster stratospheric circulations produce younger distributions for the age of air, have larger loss rates of long-lived stratospheric tracers, and therefore yield shorter CFC lifetimes (Douglass et al., 2008). The quasi-biennial oscillation (QBO) also has a significant impact on the stratospheric distributions of CFC-11 and CFC-12, in particular in the tropics (Kellmann et al., 2012). These issues are of practical relevance for the analysis of temporally and spatially limited data sets from aircraft campaigns, for instance. One example is the recent study of Laube et al. (2013), which closely followed the approach of Volk et al. (1997) to estimate the
CFC-11 / CFC-12 lifetime ratio from measurements of two aircraft campaigns in late 2009 and early 2010 in northern Europe. Laube et al. (2013) found a CFC-11 / CFC-12 lifetime ratio which is $30 \%$ larger than our combined result from the satellite data and $18 \%$ larger than the new SPARC recommendation. This larger lifetime ratio corresponds to model results (Douglass et al., 2008; Chipperfield et al., 2014), but further study would be helpful to assess possible impacts of the limited sampling characteristics of aircraft measurements. Long-term satellite data sets and model simulations bear the potential to study variability of lifetimes in detail. Brown et al. (2013) studied the hemispheric and seasonal differences based on ACE-FTS data from 2005 to 2010 and found substantial variations of the CFC-12 lifetime estimates (from 94 to 173 years), but no clear correlations with either hemisphere or season. We also analyzed the hemispheric differences of the CFC-11 / CFC-12 lifetime ratio, but found no significant differences, when taking the error estimates of the results into account. Differences in CFC-12 lifetime estimates are 9 years for MIPAS (only 1 year for the ESA data), 4 years for ACE-FTS, and 3 years for EMAC/CLaMS.

In this study we estimated the ratio of the stratospheric lifetimes of CFC-11 and CFC-12 based on the tracer-tracer method directly from zonal mean climatologies from satellite observations and atmospheric model output. We took advantage of the fact that these climatologies provide multiyear coverage, which allowed us to neglect the statistical errors of individual measurements and take significant parts of atmospheric variability into account. In contrast to other studies using satellite measurements, we found highly consistent lifetime estimates for CFC-11 and CFC-12 for the ACE-FTS, HIRDLS, and MIPAS as well as the EMAC/CLaMS model. We also found excellent agreement with the current SPARC recommendations. Nevertheless, new infrared limb or occultation satellite measurements with high vertical resolution would help to further improve CFC-11 and CFC-12 lifetime recommendations and their error estimates in future studies. 
Appendix A: Lifetime estimates for idealized CFC profiles

In order to analyze the influence of systematic measurement errors on lifetime estimates we conducted a set of tests with idealized volume mixing ratio profiles. For this purpose we constructed CFC-11 and CFC-12 profiles with a constant volume mixing ratio in the troposphere and a linear decrease towards zero in the stratosphere. The tropospheric volume mixing ratios were set to 240 and 530 ppt for CFC-11 and CFC-12, respectively. The stratospheric slopes were adapted to obtain a tracer-tracer slope of $\mathrm{d} \sigma_{2} / \mathrm{d} \sigma_{1} \approx 1.1$, which yields $\tau_{1} / \tau_{2} \approx 0.5$, corresponding to the new SPARC lifetime recommendations. Obviously, real CFC profiles show more variability and structure in the stratosphere than the idealized profiles. Nevertheless, the simple and idealized profiles were found suitable to qualitatively study the impact of vertical resolution and measurement errors on observed tracer-tracer correlations. For this purpose we convolved the idealized profiles with Gaussian weighting functions with different full width at half maximum. This vertical smoothing represents, on the one hand, the limited vertical resolution of the satellite measurements and, on the other hand, the degrading effect due to averaging of profiles from different latitudes and different measurement times, for which the tropopause height varies. Different measurement errors were imposed on the profiles to assess their influence on tracer-tracer slopes.

The results of four different test cases are presented in Fig. A1. Test case 1 is a reference case that was not degraded by any assumed measurement error, but illustrates the impact of vertical resolution. It can be seen that vertical smoothing has the largest effect around the tropopause and in the middle and upper stratosphere, where curvature of the idealized CFC profiles is largest. Other parts of the profiles are not affected at all. For test case 1 we obtained the promising result that the tracer-tracer correlations and the local slopes close to the tropopause are not affected by degraded vertical resolution at all. This might have been expected, because both CFC profiles are influenced by vertical smoothing in the same way. In reality, however, there may be differences in vertical smoothing related to the signals and constraints occurring in the CFC-11 or CFC-12 retrieval as well as differences due to averaging if the CFC-11 and CFC-12 climatologies are not derived from exactly the same subsets of data.
To illustrate the influence of systematic measurement errors of the experimental data we constructed the test cases 2 to 4 . For test case 2 we added a $10 \%$ positive bias to the CFC11 profile. This error directly maps into the tracer-tracer slopes, which are reduced by $10 \%$. In principle, such a bias would be compensated for in the lifetime analysis if the same data were used to calculate the ratio of global burdens. However, we argue that surface data are much better suited than satellite data to accurately calculate global burdens and therefore considered a constant bias as an additional term in the error analysis. For test case 3 we distorted the CFC-11 profile with an altitude-dependent bias of $1 \% \mathrm{~km}^{-1}$. This error leads to strongly decreasing slopes towards the tropopause. For test case 4 we shifted the CFC-11 profile $1 \mathrm{~km}$ upward. Such altitude displacements between the CFC profiles could arise if the climatologies are not prepared from exactly the same subsets of data, for instance. This vertical displacement also leads to significant slope errors at the tropopause. We do not expect such errors to be present in our data. However, if such errors are present it should be noted that the linear fit approach will help to reduce their influence on slope estimation.

\section{Appendix B: Electronic supplement}

We provide the zonal mean climatologies and the software used for the lifetime analysis as an electronic supplement to this paper. This allows our results to be reproduced and extended in further work. For details please see the README file contained in the supplement. 

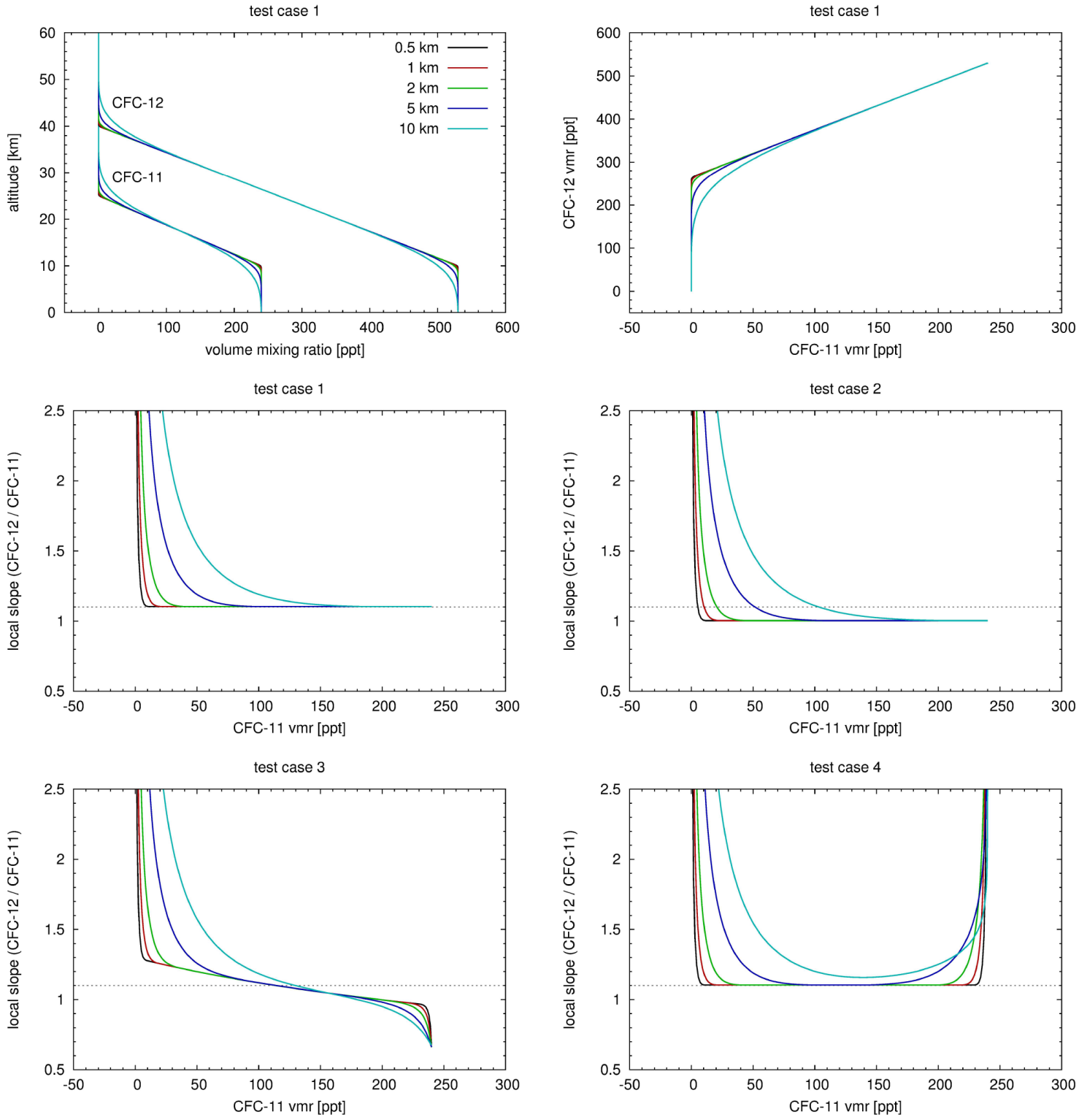

Figure A1. Idealized CFC profiles (top, left), tracer-tracer correlations (top, right), and local tracer-tracer slopes for different test cases (other). Colored curves refer to different vertical smoothing; see plot legend for full width at half maximum of the Gaussian shape function used to convolve the profiles. In test case 1 no errors are imposed on the CFC profiles. In test case 2 the CFC-11 profile has a constant $10 \%$ bias. For test case 3 we imposed an altitude-dependent error of $1 \% \mathrm{~km}^{-1}$ on the CFC-11 profile. In test case 4 the CFC-11 profile is shifted upward by $1 \mathrm{~km}$. 


\section{The Supplement related to this article is available online at doi:10.5194/acp-14-12479-2014-supplement.}

Acknowledgements. Combined CFC-11 and CFC-12 surface data sets were provided by the NOAA/ESRL Global Monitoring Division. Development of the ACE-FTS climatology was supported by grants from the Canadian Foundation for Climate and Atmospheric Sciences and the Canadian Space Agency. The Atmospheric Chemistry Experiment (ACE) is a Canadian-led mission mainly supported by the Canadian Space Agency. HIRDLS is a joint project between the UK and the USA. HIRDLS data are processed at the HIRDLS Science Investigator-led Processing System (SIPS) in Boulder, Colorado. John Gille was supported by NASA under contract NAS5-97046. Envisat MIPAS data were provided by the European Space Agency. We thank Patrick Jöckel and Nicole Thomas for support in developing the EMAC/CLaMS model. We acknowledge Jens-Uwe Grooß, Paul Konopka, and Felix Ploeger for providing climatological and initial data for the model runs. We thank Joan Alexander, Patrick Jöckel, and Steve Montzka for constructive comments on earlier drafts of this manuscript.

The service charges for this open access publication have been covered by a Research Centre of the Helmholtz Association.

Edited by: F. Khosrawi

\section{References}

Becker, G., Grooss, J.-U., McKenna, D., and Müller, R.: Stratospheric Photolysis Frequencies: Impact of an Improved Numerical Solution of the Radiative Transfer Equation, J. Atmos. Chem., 37, 217-229, doi:10.1023/A:1006468926530, 2000.

Bernath, P. F.: Atmospheric chemistry experiment (ACE): Analytical chemistry from orbit, TRAC-Trend. Anal. Chem., 25, 647-654, 2006.

Bernath, P. F., McElroy, C. T., Abrams, M. C., Boone, C. D., Butler, M., Camy-Peyret, C., Carleer, M., Clerbaux, C., Coheur, P. ., Colin, R., DeCola, P., DeMazière, M., Drummond, J. R., Dufour, D., Evans, W. F. J., Fast, H., Fussen, D., Gilbert, K., Jennings, D. E., Llewellyn, E. J., Lowe, R. P., Mahieu, E., McConnell, J. C., McHugh, M., McLeod, S. D., Michaud, R., Midwinter, C., Nassar, R., Nichitiu, F., Nowlan, C., Rinsland, C. P., Rochon, Y. J., Rowlands, N., Semeniuk, K., Simon, P., Skelton, R., Sloan, J. J., Soucy, M., Strong, K., Tremblay, P., Turnbull, D., Walker, K. A., Walkty, I., Wardle, D. A., Wehrle, V., Zander, R., and Zou, J.: Atmospheric chemistry experiment (ACE): Mission overview, Geophys. Res. Lett., 32, L15S01, doi:10.1029/2005GL022386, 2005.

Bingham, G. E., Zhou, D. K., Bartschi, B. Y., Anderson, G. P., Smith, D. R., Chetwynd, J. H., and Nadile, R. M.: Cryogenic Infrared Radiance Instrumentation for Shuttle (CIRRIS 1A) Earth limb spectral measurements, calibration, and atmospheric $\mathrm{O}_{3}$, $\mathrm{HNO}_{3}$, CFC-12, and CFC-11 profile retrieval, J. Geophys. Res., 102, 3547-3558, 1997.
Brown, A. T., Volk, C. M., Schoeberl, M. R., Boone, C. D., and Bernath, P. F.: Stratospheric lifetimes of CFC-12, $\mathrm{CCl}_{4}, \mathrm{CH}_{4}$, $\mathrm{CH}_{3} \mathrm{Cl}$ and $\mathrm{N}_{2} \mathrm{O}$ from measurements made by the Atmospheric Chemistry Experiment-Fourier Transform Spectrometer (ACEFTS), Atmos. Chem. Phys., 13, 6921-6950, doi:10.5194/acp-136921-2013, 2013.

Chipperfield, M. P., Liang, Q., Strahan, S. E., Morgenstern, O., Dhomse, S. S., Abraham, N. L., Archibald, A. T., Bekki, S., Braesicke, P., Di Genova, G., Fleming, E. L., Hardiman, S. C., Iachetti, D., Jackman, C. H., Kinnison, D. E., Marchand, M., Pitari, G., Pyle, J. A., Rozanov, E., Stenke, A., and Tummon, F.: Multimodel estimates of atmospheric lifetimes of long-lived ozonedepleting substances: Present and future, J. Geophys. Res., 119, 2555-2573, doi:10.1002/2013JD021097, 2014.

Dinelli, B. M., Arnone, E., Brizzi, G., Carlotti, M., Castelli, E., Magnani, L., Papandrea, E., Prevedelli, M., and Ridolfi, M.: The MIPAS2D database of MIPAS/ENVISAT measurements retrieved with a multi-target 2-dimensional tomographic approach, Atmos. Meas. Tech., 3, 355-374, doi:10.5194/amt-3-355-2010, 2010.

Douglass, A. R., Stolarski, R. S., Schoeberl, M. R., Jackman, C. H., Gupta, M. L., Newman, P. A., Nielsen, J. E., and Fleming, E. L.: Relationship of loss, mean age of air and the distribution of CFCs to stratospheric circulation and implications for atmospheric lifetimes, J. Geophys. Res., 113, D14309, doi:10.1029/2007JD009575, 2008.

Elkins, J. W., Thompson, T. M., Swanson, T. H., Butler, J. H., Hall, B. D., Cummings, S. O., Fisher, D. A., and Raffo, A. G.: Decrease of growth rates of atmospheric chlorofluorocarbons 11 and 12, Nature, 364, 780-783, 1993.

Eyring, V., Harris, N. R. P., Rex, M., Shepherd, T. G., Fahey, D. W., Amanatidis, G. T., Austin, J., Chipperfield, M. P., Dameris, M., Forster, P. M. D. F., Gettelman, A., Graf, H. F., Nagashima, T., Newman, P. A., Pawson, S., Prather, M. J., Pyle, J. A., Salawitch, R. J., Santer, B. D., and Waugh, D. W.: A strategy for processoriented validation of coupled chemistry-climate models, B. Am. Meteorol. Soc., 86, 1117-1133, 2005.

Fischer, H., Birk, M., Blom, C., Carli, B., Carlotti, M., von Clarmann, T., Delbouille, L., Dudhia, A., Ehhalt, D., Endemann, M., Flaud, J. M., Gessner, R., Kleinert, A., Koopman, R., Langen, J., López-Puertas, M., Mosner, P., Nett, H., Oelhaf, H., Perron, G., Remedios, J., Ridolfi, M., Stiller, G., and Zander, R.: MIPAS: an instrument for atmospheric and climate research, Atmos. Chem. Phys., 8, 2151-2188, doi:10.5194/acp-8-2151-2008, 2008.

Gille, J., Barnett, J., Arter, P., Barker, M., Bernath, P., Boone, C., Cavanaugh, C., Chow, J., Coffey, M., Craft, J., Craig, C., Dials, M., Dean, V., Eden, T., Edwards, D. P., Francis, G., Halvorson, C., Harvey, L., Hepplewhite, C., Khosravi, R., Kinnison, D., Krinsky, C., Lambert, A., Lee, H., Lyjak, L., Loh, J., Mankin, W., Massie, S., McInerney, J., Moorhouse, J., Nardi, B., Packman, D., Randall, C., Reburn, J., Rudolf, W., Schwartz, M., Serafin, J., Stone, K., Torpy, B., Walker, K., Waterfall, A., Watkins, R., Whitney, J., Woodard, D., and Young, G.: High Resolution Dynamics Limb Sounder: Experiment overview, recovery, and validation of initial temperature data, J. Geophys. Res., 113, D16S43, doi:10.1029/2007JD008824, 2008.

Gille, J., Gray, L., Cavanaugh, C., Coffey, M., Dean, V., Halvorson, C., Karol, S., Khosravi, R., Kinnison, D., Massie, S., Nardi, B., Rivas, M. B., Smith, L., Torpy, B., Waterfall, A., and Wright, 
C.: High Resolution Dynamics Limb Sounder, Earth Observing System (EOS), Data Description and Quality, Version 7 (V7), Tech. rep., National Center for Atmospheric Research, Boulder, Colorado, USA, http://www.eos.ucar.edu/hirdls/data/ products/HIRDLS-DQD_V7-1.pdf (last access: 21 June 2014), 2013.

Gille, J. C., Barnett, J. J., Whitney, J. G., Dials, M. A., Woodard, D., Rudolf, W. P., Lambert, A., and Mankin, W.: The HighResolution Dynamics Limb Sounder (HIRDLS) experiment on AURA, Proc. SPIE, 5152, 161-171, 2003.

Grooß, J.-U., Günther, G., Konopka, P., Müller, R., McKenna, D. S., Stroh, F., Vogel, B., Engel, A., Müller, M., Hoppel, K., Bevilacqua, R., Richard, E., Webster, C. R., Elkins, J. W., Hurst, D. F., Romashkin, P. A., and Baumgardner, D. G.: Simulation of ozone depletion in spring 2000 with the Chemical Lagrangian Model of the Stratosphere (CLaMS), J. Geophys. Res., 107, 8295, doi:10.1029/2001JD000456, 2002.

Hodnebrog, Ø., Etminan, M., Fuglestvedt, J. S., Marston, G., Myhre, G., Nielsen, C. J., Shine, K. P., and Wallington, T. J.: Global warming potentials and radiative efficiencies of halocarbons and related compounds: A comprehensive review, Rev. Geophys., 51, 300-378, 2013.

Hoffmann, L., Spang, R., and Riese, M.: Retrieval of chlorofluorocarbon distributions from Envisat MIPAS measurements, Proc. SPIE, 5571, 193-204, 2004.

Hoffmann, L., Spang, R., Kaufmann, M., and Riese, M.: Retrieval of CFC-11 and CFC-12 from Envisat MIPAS observations by means of rapid radiative transfer calculations, Adv. Space Res., 36, 915-921, 2005.

Hoffmann, L., Kaufmann, M., Spang, R., Müller, R., Remedios, J. J., Moore, D. P., Volk, C. M., von Clarmann, T., and Riese, M.: Envisat MIPAS measurements of CFC-11: retrieval, validation, and climatology, Atmos. Chem. Phys., 8, 3671-3688, doi:10.5194/acp-8-3671-2008, 2008.

Holton, J. R., Haynes, P. H., McIntyre, M. E., Douglass, A. R., Rood, R. B., and Pfister, L.: Stratosphere-Troposphere Exchange, Rev. Geophys., 33, 403-439, 1995.

Hoppe, C. M., Hoffmann, L., Konopka, P., Grooß, J.-U., Ploeger, F., Günther, G., Jöckel, P., and Müller, R.: The implementation of the CLaMS Lagrangian transport core into the chemistry climate model EMAC 2.40.1: application on age of air and transport of long-lived trace species, Geosci. Model Dev. Discuss., 7, 1759-1790, doi:10.5194/gmdd-7-1759-2014, 2014.

Hurrell, J. W., Hack, J. J., Shea, D., Caron, J. M., and Rosinski, J.: A New Sea Surface Temperature and Sea Ice Boundary Dataset for the Community Atmosphere Model, J. Clim., 21, 5145-5153, 2008.

IPCC: Climate Change 2013: The Physical Science Basis. Contribution of Working Group I to the Fifth Assessment Report of the Intergovernmental Panel on Climate Change, Cambridge University Press, Cambridge, United Kingdom and New York, NY, USA, 2013.

Jöckel, P., Kerkweg, A., Buchholz-Dietsch, J., Tost, H., Sander, R., and Pozzer, A.: Technical Note: Coupling of chemical processes with the Modular Earth Submodel System (MESSy) submodel TRACER, Atmos. Chem. Phys., 8, 1677-1687, doi:10.5194/acp8-1677-2008, 2008.

Jöckel, P., Kerkweg, A., Pozzer, A., Sander, R., Tost, H., Riede, H., Baumgaertner, A., Gromov, S., and Kern, B.: Development cycle
2 of the Modular Earth Submodel System (MESSy2), Geosci. Model Dev., 3, 717-752, doi:10.5194/gmd-3-717-2010, 2010.

Jones, A., Walker, K. A., Jin, J. J., Taylor, J. R., Boone, C. D., Bernath, P. F., Brohede, S., Manney, G. L., McLeod, S., Hughes, R., and Daffer, W. H.: Technical Note: A trace gas climatology derived from the Atmospheric Chemistry Experiment Fourier Transform Spectrometer (ACE-FTS) data set, Atmos. Chem. Phys., 12, 5207-5220, doi:10.5194/acp-12-5207-2012, 2012.

Kellmann, S., von Clarmann, T., Stiller, G. P., Eckert, E., Glatthor, N., Höpfner, M., Kiefer, M., Orphal, J., Funke, B., Grabowski, U., Linden, A., Dutton, G. S., and Elkins, J. W.: Global CFC-11 $(\mathrm{CCl} 3 \mathrm{~F})$ and $\mathrm{CFC}-12(\mathrm{CCl} 2 \mathrm{~F} 2)$ measurements with the Michelson Interferometer for Passive Atmospheric Sounding (MIPAS): retrieval, climatologies and trends, Atmos. Chem. Phys., 12, 11857-11875, doi:10.5194/acp-12-11857-2012, 2012.

Khosrawi, F., Müller, R., Irie, H., Engel, A., Toon, G. C., Sen, B., Aoki, S., Nakazawa, T., Traub, W. A., Jucks, K. W., Johnson, D. G., Oelhaf, H., Wetzel, G., Sugita, T., Kanzawa, H., Yokota, T., Nakajima, H., and Sasano, Y.: Validation of CFC-12 measurements from the Improved Limb Atmospheric Spectrometer (ILAS) with the version 6.0 retrieval algorithm, J. Geophys. Res., 109, D06311, doi:10.1029/2003JD004325, 2004.

Konopka, P., Steinhorst, H.-M., Grooß, J.-U., Günther, G., Müller, R., Elkins, J. W., Jost, H.-J., Richard, E., Schmidt, U., Toon, G., and McKenna, D. S.: Mixing and ozone loss in the 1999-2000 Arctic vortex: Simulations with the three-dimensional Chemical Lagrangian Model of the Stratosphere (CLaMS), J. Geophys. Res., 109, D02315, doi:10.1029/2003JD003792, 2004.

Konopka, P., Günther, G., Müller, R., dos Santos, F. H. S., Schiller, C., Ravegnani, F., Ulanovsky, A., Schlager, H., Volk, C. M., Viciani, S., Pan, L. L., McKenna, D.-S., and Riese, M.: Contribution of mixing to upward transport across the tropical tropopause layer (TTL), Atmos. Chem. Phys., 7, 3285-3308, doi:10.5194/acp-7-3285-2007, 2007.

Kuell, V., Offermann, D., Jarisch, M., Schaeler, B., Engel, A., Claude, G., Smit, H. G. J., Ebel, A., and Feldmann, H.: Tropopause region temperatures and CFC 11 mixing ratios from CRISTA 2, J. Geophys. Res., 110, D16104, doi:10.1029/2004JD005592, 2005.

Laube, J. C., Keil, A., Bönisch, H., Engel, A., Röckmann, T., Volk, C. M., and Sturges, W. T.: Observation-based assessment of stratospheric fractional release, lifetimes, and ozone depletion potentials of ten important source gases, Atmos. Chem. Phys., 13, 2779-2791, doi:10.5194/acp-13-2779-2013, 2013.

Lin, S. J. and Rood, R. B.: Multidimensional flux-form semiLagrangian transport schemes, Mon. Weather Rev., 124, 2046-2070, 1996.

Mahieu, E., Duchatelet, P., Demoulin, P., Walker, K. A., Dupuy, E., Froidevaux, L., Randall, C., Catoire, V., Strong, K., Boone, C. D., Bernath, P. F., Blavier, J.-F., Blumenstock, T., Coffey, M., De Mazière, M., Griffith, D., Hannigan, J., Hase, F., Jones, N., Jucks, K. W., Kagawa, A., Kasai, Y., Mebarki, Y., Mikuteit, S., Nassar, R., Notholt, J., Rinsland, C. P., Robert, C., Schrems, O., Senten, C., Smale, D., Taylor, J., Tétard, C., Toon, G. C., Warneke, T., Wood, S. W., Zander, R., and Servais, C.: Validation of ACEFTS v2.2 measurements of $\mathrm{HCl}, \mathrm{HF}, \mathrm{CCl}_{3} \mathrm{~F}$ and $\mathrm{CCl}_{2} \mathrm{~F}_{2}$ using space-, balloon- and ground-based instrument observations, Atmos. Chem. Phys., 8, 6199-6221, doi:10.5194/acp-8-6199-2008, 2008. 
Mahowald, N. M., Plumb, R. A., Rasch, P. J., del Corral, J., Sassi, F., and Heres, W.: Stratospheric transport in a three-dimensional isentropic coordinate model, J. Geophys. Res., 107, ACH 31-ACH 3-14, doi:10.1029/2001JD001313, 2002.

McGillen, M. R., Fleming, E. L., Jackman, C. H., and Burkholder, J. B.: $\mathrm{CFCl}_{3}$ (CFC-11): UV absorption spectrum temperature dependence measurements and the impact on its atmospheric lifetime and uncertainty, Geophys. Res. Lett., 40, 4772-4776, 2013.

McKenna, D. S., Grooß, J.-U., Günther, G., Konopka, P., Müller, R., Carver, G., and Sasano, Y.: A new Chemical Lagrangian Model of the Stratosphere (CLaMS) 2. Formulation of chemistry scheme and initialization, J. Geophys. Res., 107, ACH 4-1-ACH 4-14, doi:10.1029/2000JD000113, 2002a.

McKenna, D. S., Konopka, P., Grooß, J.-U., Günther, G., Müller, R., Spang, R., Offermann, D., and Orsolini, Y.: A new Chemical Lagrangian Model of the Stratosphere (CLaMS) 1. Formulation of advection and mixing, J. Geophys. Res., 107, ACH 15-1-ACH 15-15, doi:10.1029/2000JD000114, 2002b.

Minschwaner, K., Hoffmann, L., Brown, A., Riese, M., Müller, R., and Bernath, P. F.: Stratospheric loss and atmospheric lifetimes of CFC-11 and CFC-12 derived from satellite observations, Atmos. Chem. Phys., 13, 4253-4263, doi:10.5194/acp-13-42532013, 2013.

Molina, M. J. and Rowland, F. S.: Stratospheric sink for chlorofluoromethanes: chlorine atom-catalyzed destruction of ozone, Nature, 249, 810-812, 1974.

Morgenstern, O., Pyle, J. A., Iwi, A. M., Norton, W. A., Elkins, J. W., Hurst, D. F., and Romashkin, P. A.: Diagnosis of mixing between middle latitudes and the polar vortex from tracer-tracer correlations, J. Geophys. Res., 107, 4321, doi:10.1029/2001JD001224, 2002.

Morgenstern, O., Lee, A. M., and Pyle, J. A.: Cumulative mixing inferred from stratospheric tracer relationships, J. Geophys. Res., 108, 8321, doi:10.1029/2002JD002098, 2003.

Müller, R., Crutzen, P. J., Grooß, J.-U., Brühl, C., Russell III, J. M., and Tuck, A. F.: Chlorine activation and ozone depletion in the Arctic vortex: Observations by the Halogen Occultation Experiment on the Upper Atmosphere Research Satellite, J. Geophys. Res., 101, 12531-12554, 1996.

Müller, R., McKenna, D. S., Schmidt, U., Engel, A., and Proffitt, M. H.: The $\mathrm{O}_{3}-\mathrm{N}_{2} \mathrm{O}$ relationship from balloon-borne observations as a measure of Arctic ozone loss in 1991/92, Q. J. Roy. Meteor. Soc., 127, 1389-1412, 2001.

Müller, R., Tilmes, S., Konopka, P., Grooß, J.-U., and Jost, H.J.: Impact of mixing and chemical change on ozone-tracer relations in the polar vortex, Atmos. Chem. Phys., 5, 3139-3151, doi:10.5194/acp-5-3139-2005, 2005.

Neu, J. L. and Plumb, R. A.: Age of air in a "leaky pipe" model of stratospheric transport, J. Geophys. Res., 104, 19243-19255, 1999.

Plumb, R. A.: A “tropical pipe” model of stratospheric transport, J. Geophys. Res., 101, 3957-3972, 1996.

Plumb, R. A.: Stratospheric Transport, J. Met. Soc. Japan, 80, 793-809, 2002.

Plumb, R. A.: Tracer interrelationships in the stratosphere, Rev. Geophys., 45, RG4005, doi:10.1029/2005RG000179, 2007.

Plumb, R. A. and Ko, M. K. W.: Interrelationships between mixing ratios of long-lived stratospheric constituents, J. Geophys. Res., 97, 10145-10156, 1992.
Plumb, R. A., Waugh, D. W., and Chipperfield, M. P.: The effects of mixing on tracer relationships in the polar vortices, J. Geophys. Res., 105, 10047-10062, 2000.

Pommrich, R., Müller, R., Grooß, J.-U., Konopka, P., Ploeger, F., Vogel, B., Tao, M., Hoppe, C. M., Günther, G., Spelten, N., Hoffmann, L., Pumphrey, H.-C., Viciani, S., D’Amato, F., Volk, C. M., Hoor, P., Schlager, H., and Riese, M.: Tropical troposphere to stratosphere transport of carbon monoxide and long-lived trace species in the Chemical Lagrangian Model of the Stratosphere (CLaMS), Geosci. Model Dev. Discuss., 7, 5087-5139, doi:10.5194/gmdd-7-5087-2014, 2014.

Raspollini, P., Carli, B., Carlotti, M., Ceccherini, S., Dehn, A., Dinelli, B. M., Dudhia, A., Flaud, J.-M., López-Puertas, M., Niro, F., Remedios, J. J., Ridolfi, M., Sembhi, H., Sgheri, L., and von Clarmann, T.: Ten years of MIPAS measurements with ESA Level 2 processor V6 - Part 1: Retrieval algorithm and diagnostics of the products, Atmos. Meas. Tech., 6, 2419-2439, doi:10.5194/amt-6-2419-2013, 2013.

Riese, M., Spang, R., Preusse, P., Ern, M., Jarisch, M., Offermann, D., and Grossmann, K. U.: Cryogenic Infrared Spectrometers and Telescopes for the Atmosphere (CRISTA) data processing and atmospheric temperature and trace gas retrieval, J. Geophys. Res., 104, 16349-16367, 1999.

Rigby, M., Prinn, R. G., O’Doherty, S., Montzka, S. A., McCulloch, A., Harth, C. M., Mühle, J., Salameh, P. K., Weiss, R. F., Young, D., Simmonds, P. G., Hall, B. D., Dutton, G. S., Nance, D., Mondeel, D. J., Elkins, J. W., Krummel, P. B., Steele, L. P., and Fraser, P. J.: Re-evaluation of the lifetimes of the major CFCs and $\mathrm{CH}_{3} \mathrm{CCl} 3$ using atmospheric trends, Atmos. Chem. Phys., 13, 2691-2702, doi:10.5194/acp-13-2691-2013, 2013.

Rind, D., Lerner, J., Jonas, J., and McLinden, C.: Effects of resolution and model physics on tracer transports in the NASA Goddard Institute for Space Studies general circulation models, J. Geophys. Res., 112, D09315, doi:10.1029/2006JD007476, 2007.

Roeckner, E., Brokopf, R., Esch, M., Giorgetta, M., Hagemann, S., Kornblueh, L., Manzini, E., Schlese, U., and Schulzweida, U.: Sensitivity of simulated climate to horizontal and vertical resolution in the ECHAM5 atmosphere model, J. Clim., 19, 3771-3791, 2006.

Schoeberl, M. R., Douglass, A. R., Polansky, B., Boone, C., Walker, K. A., and Bernath, P.: Estimation of stratospheric age spectrum from chemical tracers, J. Geophys. Res., 110, D21303, doi:10.1029/2005JD006125, 2005.

Solomon, S.: Stratospheric ozone depletion: A review of concepts and history, Rev. Geophys., 37, 275-316, 1999.

SPARC: SPARC report on the lifetimes of stratospheric ozonedepleting substances, Their Replacements, and Related Species, SPARC Report No. 6, WCRP-15/2013, http://www. sparc-climate.org/publications/sparc-reports/sparc-report-no6/ (last access: 21 June 2014), 2013.

Velders, G. J. M., Andersen, S. O., Daniel, J. S., Fahey, D. W., and McFarland, M.: The importance of the Montreal Protocol in protecting climate, Proc. Natl. Acad. Sci. USA, 104, 4814-4819, 2007.

Volk, C. M., Elkins, J. W., Fahey, D. W., Salawitch, R. J., Dutton, G. S., Gilligan, J. M., Proffitt, M. H., Loewenstein, M., Podolske, J. R., Minschwaner, K., Margitan, J. J., and Chan, K. R.: Quantifying transport between the tropical and mid-latitude lower stratosphere, Science, 272, 1763-1768, 1996. 
Volk, C. M., Elkins, J. W., Fahey, D. W., Dutton, G. S., Gilligan, J. M., Loewenstein, M., Podolske, J. R., Chan, K. R., and Gunson, M. R.: Evaluation of source gas lifetimes from stratospheric observations, J. Geophys. Res., 102, 25543-25564, 1997.

Waugh, D. W.: Mixing of polar vortex air into middle latitudes as revealed by tracer-tracer scatterplots, J. Geophys. Res., 102, 13119-13134, 1997.

Waugh, D. W., Hall, T. M., and Haine, T. W. N.: Relationships among tracer ages, J. Geophys. Res., 108, 3138, doi:10.1029/2002JC001325, 2003.

WMO: Scientific Assessment of Ozone Depletion, Global Ozone Research and Monitoring Project, Report No. 44, Geneva, Switzerland, 1999.
WMO: Scientific Assessment of Ozone Depletion: 2010, Global Ozone Research and Monitoring Project, Report No. 52, Geneva, Switzerland, 2011.

Yokota, T., Nakajima, H., Sugita, T., Tsubaki, H., Itou, Y., Kaji, M., Suzuki, M., Kanzawa, H., Park, J. H., and Sasano, Y.: Improved Limb Atmospheric Spectrometer (ILAS) data retrieval algorithm for Version 5.20 gas profile products, J. Geophys. Res., 107, 8216, doi:10.1029/2001JD000628, 2002. 